

Volume 34 No.1 Janeiro-Abril 2021

\title{
MINI ASPIRADOR ADAPTADO PARA COLETA DE MICRORRESÍDUOS EM OBJETOS ARQUEOLÓGICOS
}

Ricardo França Alves dos Reis*, Sheila Maria Ferraz Mendonça de Souza**

RESUMO

A coleta de microrresíduos depositados em artefatos arqueológicos é de grande interesse científico para análises bioquímicas, biológicas e sedimentológicas. Mas tais artefatos podem apresentar superfícies irregulares e de difícil acesso, nas quais coletar amostras pode ser difícil ou impreciso. A adaptação de um mini aspirador equipado com extremidades adequadas à coleta em áreas pontuais de superfícies e orifícios estreitos, foi a solução encontrada pelos autores. O uso desse equipamento foi testado em estudo de fungos em múmias da coleção Egípcia do Museu Nacional, ocasião em que assegurou coletas rápidas, eficientes e sem contaminação cruzada, como comprovado na referida pesquisa. $O$ equipamento mostrou-se também econômico, de fácil transporte e manuseio, aplicando-se ao laboratório e ao campo, como demonstrado no presente artigo.

Palavras-chave: mini aspirador adaptado; microrresíduos; técnicas de coleta.

\footnotetext{
* Escola Nacional de Saúde Pública Sergio Arouca - ENSP/Fiocruz, Departamento de Endemias Samuel Pessoa. E-mail: ricardofranca.reis@gmail.com. ORCID: https://orcid.org/0000-0001-6327-9473.

** Escola Nacional de Saúde Pública Sergio Arouca - ENSP/Fiocruz, Departamento de Endemias Samuel Pessoa. E-mail sferraz@ensp.fiocruz.br. ORCID: http://orcid.org/0000-0001-5054-0126.
} 


\section{ADAPTED MINI VACUUM CLEANER FOR SAMPLING MICRO-RESIDUES IN ARCHAEOLOGICAL OBJECTS}

\section{ABSTRACT}

The recovery of micro-residues in archaeological artifacts is of great scientific interest for biochemical, biological, and sedimentological analysis. Otherwise, these artifacts could have irregular surfaces and hard-to-reach areas in which sampling may be difficult or inaccurate. Adapting a mini vacuum device, with special collecting extremities, was very useful for the authors to collect microresidues in punctual areas and tight orifices. The instrument was tested in a study of fungi in mummies of the Egyptian collection of the National Museum, and its use accelerated adequate sampling without cross-contamination, as proved by the results. The equipment is also economic, of easy transport and manipulation, and can be used in the laboratory as in fieldwork, as discussed in this article.

Keywords: adapted mini vacuum cleaner; micro-residues; sampling techniques.

\section{MINI ASPIRADORA ADAPTADA PARA MUESTREO DE MICRORESIDUOS EN OBJETOS ARQUEOLÓGICOS}

\section{RESUMEN}

La recuperación de microrresiduos en artefactos arqueológicos es de gran interés científico para análisis bioquímicos, biológicos y sedimentológicos. Pero estos artefactos pueden tener superficies irregulares y áreas de difícil acceso, en las cuales el muestreo puede ser difícil o impreciso. La adaptación de una mini aspiradora, equipada con extremidades especiales, para recolectar microrresiduos en áreas puntuales, superficies y orificios pequeños, fue la solución propuesta por los autores. El instrumento fue probado en un estudio de hongos en momias de la colección egipcia del Museo Nacional y favoreció el muestreo rápido y eficiente sin contaminación cruzada, como lo demuestran los resultados. El equipo resultó ser económico, de fácil transporte y manipulación, aplicable al laboratorio y al campo, como explica este artículo.

Palabras clave: mini aspiradora; microrresiduos; técnicas de muestreo. 


\section{INTRODUÇÃO}

A utilização de mini aspiradores para microrresíduos é geralmente feita durante a limpeza de objetos domésticos, como por exemplo, teclados de computadores, circuitos eletrônicos, mesas de escritório e até mesmo pequenos utensílios decorativos, como porta-retratos e suvenires. No presente artigo, buscamos demonstrar que tais aspiradores também podem ser ferramentas úteis para a coleta de amostras de microrresíduos em artefatos e outros materiais arqueológicos. Em tais situações, podemos encontrar partículas ou exemplares da microbiota provenientes de seus lugares de origem, ou derivadas da sua degradação, depositadas na sua superfície, em interstícios ou cavidades e ranhuras.

Esses resíduos podem abrigar microrganismos, como fungos e bactérias, provenientes do ambiente, da sua manipulação, das embalagens e transporte, e mesmo transportados por vetores biológicos como insetos e roedores presentes nos ambientes de depósito dos objetos (VALENTÍN, 2012). Tais microrganismos podem estar ativos, sendo observado o seu desenvolvimento nas peças, ou inativos, quando são observadas apenas estruturas de resistência como os conídios fúngicos e os esporos bacterianos (GONZÁLEZ, 2015). Assim sendo, a captura adequada de tais amostras dos resíduos cria oportunidades para a realização de análises bioquímicas, análises físico-químicas, e mesmo análises microbiológicas microscópicas ou por outras técnicas, as quais permitirão confirmar a sua presença ou ausência.

Tais análises podem ajudar a contar o histórico das peças. Considerando os microrganismos presentes, espécies derivadas de ambientes específicos podem estar relacionadas com a sua deterioração, ou mesmo com os processos de conservação empregados nas peças, ajudando assim a compor o seu histórico (VALENTÍN, 2012). Muitos dos objetos também podem reter agentes químicos, como pesticidas, cuja presença pode contaminar os profissionais e o ambiente (LIMA E SILVA, 2007). O uso de equipamentos adequados para obtenção das amostras para análise, evitando colocar em risco os objetos e, ao mesmo tempo, garantindo a adequação da coleta, poderá ser útil, tanto à sua análise, quanto à sua curadoria.

Em muitos casos, é suficiente a remoção superficial de camadas ou materiais depositados, a coleta de resíduos retidos em espaços e cavidades do objeto, ou a remoção de fragmentos de sua estrutura. A depender do tipo de análise que se queira fazer, o procedimento deverá sempre, entre outros aspectos, considerar a necessidade de abordagem conservadora e econômica, minimizando modificações ou perdas desnecessárias nos materiais. Técnicas tradicionais, como o uso de pinças, bisturis, tesouras e outras também têm sido descritas na literatura que menciona a coleta de amostras, causando diferentes impactos sobre a superfície amostrada.

Entretanto, apesar de sua importância, a captura de amostras de microrresíduos pode apresentar-se como um grande desafio, a depender das características do material onde estão depositados. Muitas vezes é necessário coletar em áreas de difícil acesso aos pincéis, pinças e outros instrumentos utilizados em laboratório. A dificuldade nas coletas de microrresíduos, principalmente aquelas para estudos microbiológicos, entretanto, também implica um detalhe muitas vezes pouco referido na literatura, que é assegurar que cada amostra seja completamente isolada e independente das demais, evitando-se dessa forma que ocorram a contaminação cruzada e resultados enviesados.

Diversos tipos de deposição sobre objetos podem dificultar a identificação da topografia superficial, da textura e até da cor do objeto, sendo derivados de resíduos originados em seus locais de deposição, acumulados pelo seu uso, ou provenientes dos locais onde foram mantidos. Aí estão incluídos também materiais aplicados intencionalmente para controle de pragas, por exemplo. No caso de objetos 
arqueológicos, mesmo após sua higienização, a depender das técnicas empregadas, ainda podem ser encontrados, por exemplo, microrresíduos de solo provenientes dos locais de origem (ODDY, 1999 apud GRANATO, 2007). Tais deposições, além das implicações imediatas da sua presença, podem ser fonte para conhecimento da história dos objetos.

Para Granato (2007) deve-se considerar o que deve ou não ser removido dos objetos e, durante a higienização das peças, também são importantes cuidados para evitar a perda de informações que podem estar contidas nas camadas depositadas sobre eles. Desse modo, as coletas de amostras de microrresíduos ganham ainda maior relevância, reforçando a importância das abordagens interdisciplinares nos procedimentos de conservação. $\mathrm{O}$ mesmo autor ressalta que, sempre que possível, amostras devem ser obtidas e devem ser registradas as evidências da interação das peças com o meio ambiente durante o processo de limpeza.

Koller (2000) também refere os aspectos positivos da permanência de resíduos que se acumularam ao longo do tempo em obras de arte, como pinturas e monumentos. Segundo o autor, a higienização e restauro de tais objetos é um processo irreversível que apaga o registro temporal e a sua história. Nesse sentido, a coleta de amostras de microrresíduos, em paralelo aos procedimentos de conservação e restauro, pode ser uma forma de apoiar a identificação dos processos que se deram ao longo da vida do objeto, proporcionando material para realização de testes in vitro, visando o desenvolvimento de formas de intervenção específicas nas peças (TOCCHETTO et al., 2017).

As coletas de amostras para análises aqui mencionadas exigem precisão para resultados confiáveis, favorecendo a busca da evidência microbiológica, através da análise morfológica microscópica, realização de culturas controladas em laboratório ou análises bioquímicas. Coletas independentes e conservadoras, de pouco impacto sobre os objetos, evitam a contaminação das superfícies amostradas, seja pelos materiais em suspensão no ambiente de coleta, seja pelo manuseio/instrumentos de coleta. A contaminação cruzada, outro problema que deve ser evitado, resulta da impossibilidade de garantir que cada amostra seja coletada sem contato com as demais e seja mantida completamente isolada até o momento de sua análise ou cultivo.

A realização de uma coleta em ambiente controlado, como em um laboratório, é importante, mas em muitos casos as coletas devem ser realizadas nas próprias reservas, salas de exposição ou laboratórios de museus e outras instituições detentoras de acervos, sem os recursos de laboratórios especializados. Nesses casos, o uso de equipamentos adequados garante coletas mais seguras.

Durante uma coleta, partículas das áreas amostradas podem, involuntariamente, ser dispersadas, seja pelo uso dos instrumentos ou pelo manuseio, deslocando-se para outras partes dos objetos. Nesse caso, passarão a ser detectadas também em partes diferentes daquelas onde estavam originalmente depositadas, além do que, a presença de agentes biodeteriorantes em tais partículas pode favorecer o surgimento de novos focos de contaminação nas peças, prejudicando a sua conservação (VALENTÍN, 2012). Reduzir a mobilização de micropartículas também é vantajoso.

O potencial de materiais pulverizados para abrigar microrganismos é grande. A coleta e análise de amostras pulverizadas é, assim, adequada para a busca de diversos contaminantes biológicos como esporos, alérgenos e metabólitos fúngicos, endotoxinas bacterianas, ácaros, fragmentos de insetos e descamações de tecidos de organismos. Contudo, a interpretação dos resultados das coletas pode ser difícil, dada a diversidade de contaminação presente, a qual se relaciona a múltiplos fatores presentes e passados, inclusive a movimentação das pessoas no ambiente e o nível de limpeza (GONZÁLEZ, 2015). 
Portanto, a obtenção de informações sobre o ambiente para controle da coleta no objeto também é importante. O material depositado sobre superfícies do ambiente pode ser coletado com colher ou espátula, mas frequentemente é feita a coleta com um aspirador convencional equipado com um filtro HEPA (High Efficiency Particulate Air), de alta eficiência para partículas, inclusive virais. Também pode ser empregado cassete com filtro de 37 ou $25 \mathrm{~mm}$, acoplado a uma bomba de sucção. Para esse procedimento, que proporciona amostras-controle, delimita-se a área a ser amostrada e se aspira a uma certa velocidade, como por exemplo $1 \mathrm{~m}^{2} / 1$ - 2 min, percorrendo em uma direção, depois em outra, perpendicularmente à anterior. Após a coleta da amostra, os contaminantes são extraídos usando-se o meio mais adequado, e analisados por meio da técnica mais apropriada (GONZÁLEZ, 2015). O uso da aspiração como técnica de coleta das amostras nos objetos, portanto, poderia ser pensada também como solução para estudo de contaminação a partir de microparticulados.

Dessa forma, para atender aos desafios da coleta de amostras microbiológicas durante a pesquisa para a dissertação de Mestrado do primeiro autor, Isolamento $e$ identificação de fungos em amostras retiradas de múmias egípcias da coleção do Museu Nacional do Rio de Janeiro, é que foi desenvolvido e testado, com bons resultados iniciais, um protótipo adaptado de micro aspirador. Testado e depois utilizado com sucesso para coletas das amostras, passa a ser apresentado neste artigo como exemplo de inovação bem sucedida para aplicação em coletas microbiológicas em objetos arqueológicos.

Muito embora muitas das técnicas atualmente disponíveis, como espectrofotometria, volumetria, turbidimetria, potenciometria, entre outras, permitam análises físico-químicas precisas que dispensam a retirada de amostras físicas, o mesmo não se dá para análises microbiológicas, sejam elas bioquímicas, microscópicas ou cultivo de microrganismos presentes, que ainda demandam coleta física de amostras. A obtenção de amostras por meios alternativos de coleta de poeira superficial está descrita na literatura, sendo importante que se desenvolvam estudos para padronização das técnicas, determinação de sua acurácia, e outros controles (ASHLEY et al. 2007). Esse, entretanto, não foi o propósito do trabalho que permitiu desenvolver a presente técnica, cuja validação deverá ser feita após seu uso sistemático e controlado em uma série experimental especificamente desenhada para tal.

A presente publicação tem por objetivo, portanto, apresentar esse modelo de adaptação, desenvolvido para o estudo realizado no acervo egípcio do Museu Nacional do Rio de Janeiro pelo primeiro autor, sob orientação da segunda autora. Enquanto protótipo, esse modelo de adaptação, inclusive, já foi encaminhado à análise de viabilidade de patente através do sistema GESTEC-NIT da Fundação Oswaldo Cruz, sendo confirmado seu ineditismo, conforme processo SG 188/14, pela Comissão de Propriedade Intelectual (COPAT) da mesma Fiocruz.

\section{O PROBLEMA}

No trabalho empírico nem sempre contamos com as condições que atendem às necessidades impostas por uma pesquisa, e os problemas encontrados na prática de um laboratório desafiam os pesquisadores e técnicos a buscarem soluções adequadas, muitas vezes inovadoras. No caso das pesquisas com material arqueológico, pode ser necessário desenvolver, ou adaptar, ferramentas adequadas para a coleta de amostras, já que os materiais podem variar sob diversos aspectos, como tamanho e formato, presença de material orgânico ou não, presença de materiais agregados ou não.

A busca por microrganismos e outras evidências biológicas em múmias do acervo do Museu Nacional já havia sido realizada anteriormente, com instrumentos como pinças, tesouras e seringas para aspiração. Para procedimentos de higienização das peças, 
por sua vez, fez-se o uso de micro aspiradores, em diferentes ocasiões, quando foram pontuados alguns problemas, tais como tempo de coleta, perdas em amostras pequenas, contaminação e outros.

Ao realizar a curadoria e análise de fardos de lactentes provenientes do vale do rio Chillon, Peru (SOUZA et al., 2006), mini aspiradores foram utilizados, permitindo obtenção de amostras mais adequadas para estudo microbiológico (SOUZA et al., 2008). Da mesma forma, durante procedimentos para higienização do corpo mumificado da mulher denominada KHERIMA, da coleção egípcia do Museu Nacional (SOUZA, 2009), o emprego dos mini aspiradores mostrou-se eficiente e adequado, ajudando na remoção de micro resíduos de vidro retidos superficialmente na trama do linho das bandagens (RELATÓRIO TÉCNICO, inédito).

Por outro lado, durante a revisão das condições de conservação da múmia HORI, também da coleção Egípcia do Museu Nacional, no ano de 2000, quando foi necessário realizar coletas microbiológicas pontuais, nas áreas da peça onde havia suspeita de crescimento de fungos, foram utilizados suabes e seringas para a obtenção de amostras, confirmando as dificuldades com esses recursos.

A partir das tentativas anteriores, e das referências na literatura, os autores sentiram a necessidade de coletas mais precisas, que garantissem amostras suficientes e com bom isolamento, e cuja realização demandasse menos tempo. Sobretudo quando o objetivo eram coletas residuais, de amostras pulverizadas, percebeu-se a necessidade de técnica que permitisse maior controle dos riscos de contaminação atendendo, ao mesmo tempo, os cuidados com a preservação dos objetos e a coleta adequada e suficiente para identificação dos fungos.

A proposta de realização do estudo na múmia HORI, da coleção egípcia do Museu Nacional, era especialmente problemática pelo estado do objeto. Principalmente porque a contaminação e deterioração progressivas da múmia eram percebidas pelos curadores como risco para a saúde das equipes do Museu. Foi necessário propor metodologia experimental adequada e técnica que minimizassem os impactos da coleta sobre o objeto frágil. Além das dificuldades anteriores, principalmente a importância de evitar contaminação cruzada das amostras, havia a necessidade de captura de material em áreas mais profundas da peça, como frestas e orifícios, entre pregas do tecido de linho e assim por diante. A solução veio através da proposta de adaptação de um mini aspirador.

$\mathrm{Na}$ retirada de amostras para análise, portanto, todos os cuidados deveriam ser tomados para preservar a estrutura do material, evitando que o contato com o instrumento utilizado para a coleta causasse quebra ou fragmentação, raspagem excessiva da superfície, remoção indevida de fragmentos, além de evitar espalhamento de resíduos sobre outras partes da peça.

Tal como preconizado, a coleta foi feita sempre que fosse detectada a presença de alterações de cor, materiais depositados na superfície, diferença no grau de integridade dos tecidos, entre outras alterações de aspecto do objeto. O material retirado, ainda que mínimo, deveria ser proveniente apenas das áreas-alvo, de modo a conter o material para a análise desejada tal como preconiza Valentin (2012). Por esse motivo, o instrumento de coleta foi adaptado conforme as características das superfícies do objeto. Os instrumentos mais utilizados: suabes, pinças, tesouras e lâminas de bisturis, apresentavam vantagens e desvantagens, entre elas poder causar danos secundários. Além disso, eram muitas vezes inadequados para a captura eficiente de amostras pulverizadas.

Muito embora indicados para a coleta de contaminantes biológicos, os suabes, por exemplo, são desenhados para coleta de amostras em objetos lisos e consistentes, em geral úmidos. É necessário atritar o suabe na superfície para assegurar que foi recolhido 
material suficiente para análise (CAYCHO et al., 2010). No caso do material em estudo, isso poderia implicar em alterações superficiais indesejadas.

Em alguns casos, é recomendado para a coleta de amostras biológicas o uso de esponjas estéreis úmidas usadas em superfícies amplas e irregulares (GONZÁLEZ, 2015), o que também não seria adequado. Essas, além de criarem atrito com a peça, favorecendo sua fragmentação, deixariam umidade na superfície, favorecendo a formação de biofilme prejudicial ao material egípcio.

As pinças são muito empregadas e favorecem a captura de amostras desprendidas, ou de fragmentos cortados com tesoura e/ou bisturi, entretanto, não penetram em aberturas menores, e se utilizadas para captura de material pulverizado provocam espalhamento de partículas.

Já as tesouras e bisturis, embora úteis para cortes de partes específicas, também poderiam provocar o espalhamento de resíduos do corte, e seu formato não seria adequado para recolha de amostras particuladas ou pulverizadas. Ainda que os bisturis favoreçam captura de amostras por raspagem, também causam atrito com o objeto (GONZÁLEZ, 2015), exigindo grande habilidade e treinamento para retirada de amostras com danos mínimos, não sendo igualmente adequado.

$\mathrm{O}$ estudo de corpos mumificados enquadrava-se, portanto, em condições que exigiam cuidados especiais, como precisão na coleta e mínimo impacto sobre o objeto. Dessa forma, o problema a ser solucionado para múmias egípcias era coletar amostras suficientes e reduzir os riscos de perdas na superfície a ser estudada, extremamente frágil. Ao mesmo tempo, minimizar o risco de espalhamento de resíduos e, consequentemente, a contaminação do ambiente e de outras áreas da própria peça. Finalmente, evitar ao máximo perdas das amostras que seriam mínimas, impedindo a contaminação cruzada, entre o ambiente e as partículas coletadas, e de uma amostra para outra.

Balout e Roubet (1986), em seu clássico sobre a múmia de Ramsés II, quando ela foi levada até a França para tratamento e análise, realizaram estudos fúngicos baseados na obtenção de amostras da cavidade abdominal e das bandagens de linho que envolviam o corpo. Essas foram constituídas tanto por fragmentos aleatórios, naturalmente desprendidos e coletados com pinça durante processo de tratamento da peça, como amostras pulverizadas de 0,05 - 0,10 g coletadas com espátula metálica. Tais amostras foram depois transferidas para meio de cultura adequado. A escolha dos locais de coleta baseou-se em variações de cor, presença de materiais depositados na superfície, fragmentação da peça, e assim por diante.

Arya et al. (2001), utilizaram o método de exposição de placa com meio de cultura para coletar amostras do ar ambiente, bem como coleta com fita de celofane para amostras de pontos esbranquiçados sugestivos da presença de fungos no corpo e no caixão de uma múmia egípcia do museu Baroda, em Vadodara, Índia. A fita foi posicionada sobre os pontos e inoculada posteriormente em placa de Petri, com meio de cultura adequado para o crescimento fúngico. Os autores mencionam que amostras derivadas da poeira presente na superfície da múmia e no caixão foram transferidas assepticamente para tubos com meio de cultura, mas não indicam como foram coletadas.

López-Martínez et al. (2007) utilizaram a coleta em quadrados de carpete estéril já descrita anteriormente (MARIAT; ADAN-CAMPOS, 1967) para amostras das paredes de uma cripta, e de partes da pele e de vestimentas de múmias do museu de El Carmen, Cidade do México. Essa técnica, utilizada também na microbiologia clínica para a coleta de amostras em lesões na pele ou no coro cabeludo, consiste na fricção dos quadrados de carpetes na área a ser amostrada, com a posterior semeadura em placas de Petri com meio de cultura específico. Amostras do ar também foram coletadas pela técnica de exposição de placas de Petri abertas, colocadas no chão da cripta. Não foi relatada a presença de 
material pulverizado depositado sobre os corpos, porém a aspiração poderia ser uma técnica complementar por permitir a coleta sem contato direto com as superfícies.

Caycho et al. (2010), em trabalho realizado no museu Adolfo Bermúdez Jenkis de Ica, Peru, utilizaram a técnica de quadrados de carpete para coletar amostras das paredes internas do Museu e a técnica de coleta por meio de suabes com água peptonada a $0,1 \%$, para amostras de mantos, tecidos e de superfícies de múmias, a fim de cultivá-las em meios específicos. O esfregamento, entretanto, como já dito anteriormente, acarreta perdas superficiais, sendo contraindicado em materiais mais frágeis.

Abdel-Kareem (2010a), ao coletar amostras de tecido deteriorado armazenadas em depósitos do Museu Egípcio e do Museu Cóptico do Cairo, no Egito, utilizou duas técnicas distintas. Coleta de fibras deterioradas desprendidas de objetos têxteis antigos, por meio de pinça esterilizada e, alternativamente, a técnica de coleta com suabes, esfregados no tecido antigo somente nas as áreas de suposto crescimento fúngico. Essa escolha, segundo o próprio autor, teria se dado porque a retirada de fragmentos é um método destrutivo.

Rajendran e Prasad (2012) utilizaram dois métodos diferentes para coletar amostras do ar dos ambientes internos e externos do Templo Sekharaipuram Vishnu em Kerala, Índia. Seu estudo avaliativo dos processos de biodeterioração de pinturas de murais usou um amostrador de ar automático, que opera com a impactação de partículas sugadas do ar, e o associou com a exposição de uma placa de Petri, com meio de cultura, colocada nos ambientes interno e externo do templo para coletas do ar, já que não foram coletadas amostras diretamente das pinturas.

A literatura sobre isolamento e análise de microrganismos presentes em materiais arqueológicos, especialmente aquela voltada para corpos mumificados, é uma área especializada. Muito embora seja cada vez mais exigente de técnicas e soluções na literatura consultada, conforme exemplos acima, o uso da aspiração de microrresíduos sobre os objetos é praticamente ausente da literatura, ainda que referida para amostras do ambiente. Os estudos consultados na literatura privilegiam a identificação dos taxa presentes, pouco comparando as técnicas de coleta para estudos de microrganismos. Assim, a definição do procedimento de aspiração e sua padronização para a pesquisa do Mestrado foi feita com base nos pressupostos adotados na microbiologia biomédica, onde os procedimentos de aspiração são muito utilizados. Essa experiência biomédica norteou também o uso de paramentação completa da equipe durante o trabalho.

Ainda que técnicas de aspiração, de amplo uso sanitário e biomédico (SBPC, 2014), contando com equipamentos especialmente adaptados, esteja presente em estudos do ambiente para coleta ativa de amostras de ar, por exemplo (VALENTÍN, 2007, 2012; RAJENDRAN; PRASAD, 2012; GONZÁLEZ, 2015), o levantamento feito à época, e mesmo sua complementação atual, chama atenção pela ausência do uso de aspiração para coleta nos objetos, tendo em vista a praticidade e eficácia da técnica. Isso foi atribuído à necessidade de equipamentos especialmente desenhados para esse fim, e por tratar-se de uma interface disciplinar. Referências ao uso de aspiração como técnica de higienização, por outro lado, já sugeriam que seria possível adaptar um aspirador, como em Spinelli (2010), pela inclusão de filtro de pano no bocal do tubo de um aspirador semi-industrial, para evitar a entrada de partículas de papel no equipamento, durante a limpeza de livros e documentos. Entretanto, o interesse do mini aspirador adaptado enquanto inovação para este fim só foi possível após a conclusão do Mestrado, quando se confirmou pela prospecção de registros e inovações em desenvolvimento, seu potencial.

Trabalhos mais recentes e apresentados após o desenvolvimento do mini aspirador adaptado vêm mostrando que inovações em aspiradores continuaram ocorrendo, quando a intenção foi a higienização ou tratamento de materiais com valor histórico ou cultural. 
Isso porque tais inovações permitem que sejam feitas remoções de material agregado, respeitando-se as características das peças, minimizando os riscos de danificá-las durante os tratamentos, evitando o desperdício de tempo durante os trabalhos e assegurando o conforto e preservação da saúde dos profissionais envolvidos.

Gross et al. (2017), por exemplo, utilizaram um micro aspirador adaptado para sucção controlada por meio de bicos de vidro e ponteiras, conectados a uma forte bomba de sucção, para teste preliminar na higienização de duas pinturas da Fundação Beyeler, em Basel, Suíça. O aspirador permitiu aos autores realizarem a remoção de partículas sólidas e líquidas de pequenas áreas superficiais nas pinturas, com uma sucção regulada para cada área. O dispositivo utilizado consistia em uma bomba de membrana a vácuo móvel, de aplicação na área médica, modificada para o uso em conservação. $\mathrm{O}$ vácuo produzido pelo aparelho permitiu uma sucção completa e imediata dos líquidos, deixando as superfícies secas novamente. Uma variedade de bicos, ponteiras e escovas poderiam ser acopladas ao tubo de aspiração, permitindo diversas e precisas opções de tratamentos de limpeza das peças.

Portanto, apesar de não ter sido encontrada, à época, referências específicas à técnica de aspiração como ferramenta complementar, ou substitutiva, para coletas na superfície e reentrâncias de bens arqueológicos, as poucas experiências anteriores e usos tradicionais no campo biomédico levaram a entender que essa poderia ser uma solução para o trabalho. Foi feita, portanto, a proposta de desenvolvimento tecnológico de uma ferramenta que fosse principalmente voltada para causar menos impacto físico nas superfícies amostradas, em comparação com o uso de meios de coleta mecânicos por atrito.

O uso anterior de micro aspirador pela segunda autora, já confirmara sua eficiência aprovada inclusive pela curadoria do Museu, sugerindo que o uso de equipamento de aspiração poderia ser a solução. A vantagem de agilizar com segurança as coletas, ampliando seu número, já que a utilização de tesouras e bisturis para coletas biológicas torna o trabalho mais lento, pois exige a esterilização das extremidades a cada coleta, ou a troca de instrumento aumentando a quantidade de ferramentas necessárias para uma sequência de coletas, reforçou a escolha.

Além disso, com a aspiração passou a ser possível ampliar a abrangência das coletas, que passariam assim a ser feitas também nas partes mais estreitas e internas dos objetos, com a vantagem de assegurar localização pontual das amostras, sempre que isso fosse relevante (no caso de fungos, localizar possíveis áreas de crescimento de micélio em cavidades ou fendas do objeto, por exemplo), evitando ainda a transferência de contaminantes de ponto a ponto na própria peça.

\section{BREVE HISTÓRICO - CRIAÇÃO DE UM MODELO DE UTILIDADE ADAPTADO}

Não havendo no mercado equipamento que permitisse atender às necessidades apontadas, criou-se a adaptação com base no mesmo tipo de equipamento já utilizado anteriormente para procedimentos de higienização, já testado pela sua capacidade de aspiração suave, baixo custo e fácil manejo.

A partir desse equipamento, de baixo custo e facilmente encontrado no comércio, foi desenhado e testado um modelo de utilidade adaptado que satisfez as condições iniciais, e cujo uso foi aprovado no decorrer do Mestrado. Cabe ressaltar que o objetivo do Mestrado foi a análise dos fungos presentes nos materiais analisados, não a testagem e validação técnica do aparelho desenvolvido, prestando-se apenas ao teste de protótipo, sendo seu uso ajustado de modo a permitir resultados suficientes para a coleta das amostras necessárias ao cultivo dos fungos em laboratório, levando em conta o prazo curto (24 meses) vigente para o Mestrado. Por essa razão, não chegaram a ser realizados 
testes comparativos detalhados para diferentes tipos de coletas, estudos quantitativos de desempenho e outros.

Uma vez que não havia recursos específicos para o custeio de desenvolvimento do equipamento por especialistas, ou fabricação de peças especiais, a proposta levou em conta a facilidade de acesso a materiais disponíveis em laboratório e de baixo custo do produto. Por outro lado, entendeu-se ser esse um caminho adequado, visado a necessidade de laboratórios de arqueologia, geralmente carentes de recursos em geral.

O Mini Aspirador Adaptado- MAA, foi desenvolvido a partir do modelo 0278 da empresa Bright ${ }^{\circledR}$ mostrado aqui na Figura 1.

Figura 1 - Aparelho mini aspirador modelo 0278 da Bright $\circledast$.

Fonte: https://www.shopfacil.com.br/mini-aspirador-portatil-0278-bright-3980388/p.



Equipado com um mini motor DC 3 - 6 V, com velocidade de 5000 - $10000 \mathrm{rpm}$, funcionando com até 4 pilhas AA 1,5 V, o mini aspirador a partir do qual foram feitas as adaptações é indicado pelo fabricante para higienização de equipamentos eletrônicos. Por ter seu design adequado, permite aspirar em espaços estreitos e de difícil acesso, como os encontrados nos teclados de computador e em placas ou circuitos eletrônicos. Com tubo de aspiração dotado de angulação adequada, permite manuseio confortável e acesso a diferentes partes do objeto aspirado. Promovendo aspiração suave, remove sujidades e poeira, ou detritos pulverizados, sem remover ou tracionar os tecidos, mesmo em áreas rotas.

Para a coleta de material destinado a análises microbiológicas, entretanto, o desenho do equipamento mostrava-se insuficiente. Suas extremidades não permitiriam coletas pontuais precisas, nem davam acesso a partes profundas e estreitas dos objetos, nem permitiriam isolar o aspirado do sistema de condução e ventilação do aparelho, sendo assim necessária sua adaptação.

A criação do protótipo do modelo de utilidade foi antecedida pelo desenho e teste de algumas alternativas de peças que poderiam compor a adaptação. No mini aspirador foram testados tubos de diferentes formas e tamanhos, disponíveis nos laboratórios biomédicos. Foram consideradas sua disponibilidade e adequação de formato, de modo que se encaixassem perfeitamente ao aparelho. Foram testadas também ponteiras de pipeta de diferentes tamanhos, de modo a obter encaixes adequados aos tubos. A haste de 
sucção do aparelho, por exemplo, por possuir cerca de $0,5 \mathrm{~cm}$ de diâmetro, não penetrava em aberturas com diâmetro menor, como as observadas nos corpos mumificados.

Primeiro, foi definido o tubo e a ponteira mais adequados, e o melhor desenho de sua composição, de modo a formar a extensão da extremidade do aspirador adequada a diferentes tipos de coletas. A seguir, foi necessário solucionar a questão do isolamento e segurança das amostras coletadas, seu translado para os ambientes de análise e posterior descarte. Foram feitos testes para a criação de filtros a partir de chumaços de algodão, de modo a assegurar a retenção das amostras aspiradas e, ao mesmo tempo, sua proteção/isolamento do ambiente externo. $\mathrm{O}$ filtro de tamanho ideal deveria ser capaz de reter as amostras, isolando-as do ambiente interno dos condutos através dos quais se faz a aspiração. Deveria também ser pequeno o suficiente para sua introdução e fixação na extremidade de coleta, mas suficiente para ali permanecer sem ser sugado pelo aparelho durante a aspiração, ou interromper o fluxo de ar, a ponto de impedir a sucção da amostra. A solução foi um filtro duplo.

Outro problema a ser resolvido foi a abertura das ponteiras, que por terem diâmetro muito reduzido, eram facilmente obstruídas durante a aspiração, impedindo que uma quantidade maior de material pudesse ser coletada. Após testes com material pulverizado, poeira depositada em superfícies do laboratório, fragmentos de grafite e alguns outros, foi possível encontrar a forma e dimensões mais adequadas.

A adaptação consistiu na fixação, na extremidade da haste de sucção do aspirador, de um tubo criogênico de $2 \mathrm{ml}$ da Greiner Bio-One (122263-TRI), medindo 4,8 cm x 1,06 $\mathrm{cm}$. Para o encaixe perfeito entre as partes, o fundo do tubo foi cortado, e o diâmetro da extremidade de sucção da haste foi ligeiramente reduzido. Já na abertura original do tubo, área de rosqueamento da tampa, foram adaptadas ponteiras de pipeta de $1 \mathrm{ml}$, modelo Eppendorf, descartáveis, com 7,0 cm de comprimento e diâmetro de 1,0 cm na abertura posterior. A escolha de uma extremidade removível desse tipo permitiu seu encaixe a cada coleta e sua retirada, com o conteúdo coletado no seu interior, para serem levadas diretamente para semeio no laboratório, tornando desnecessária transferência da amostra coletada, minimizando perdas e contaminação. O encaixe adaptado das ponteiras foi possível devido ao diâmetro de sua parte posterior ser cerca de $0,06 \mathrm{~cm}$ menor do que o do tubo, sendo $1,0 \mathrm{~cm}$ o da ponteira e $1,06 \mathrm{~cm}$ o do tubo (Figura 2).

Figura 2 - Mini aspirador com as respectivas adaptações para coletas: A) Tubo criogênico encaixado na haste de sucção do aparelho para permitir o perfeito encaixe das ponteiras;

B) Ponteira de pipeta de $1 \mathrm{ml}$; C) Dois chumaços de algodão para retenção do material aspirado. Foto de Ricardo França Alves dos Reis (2020).

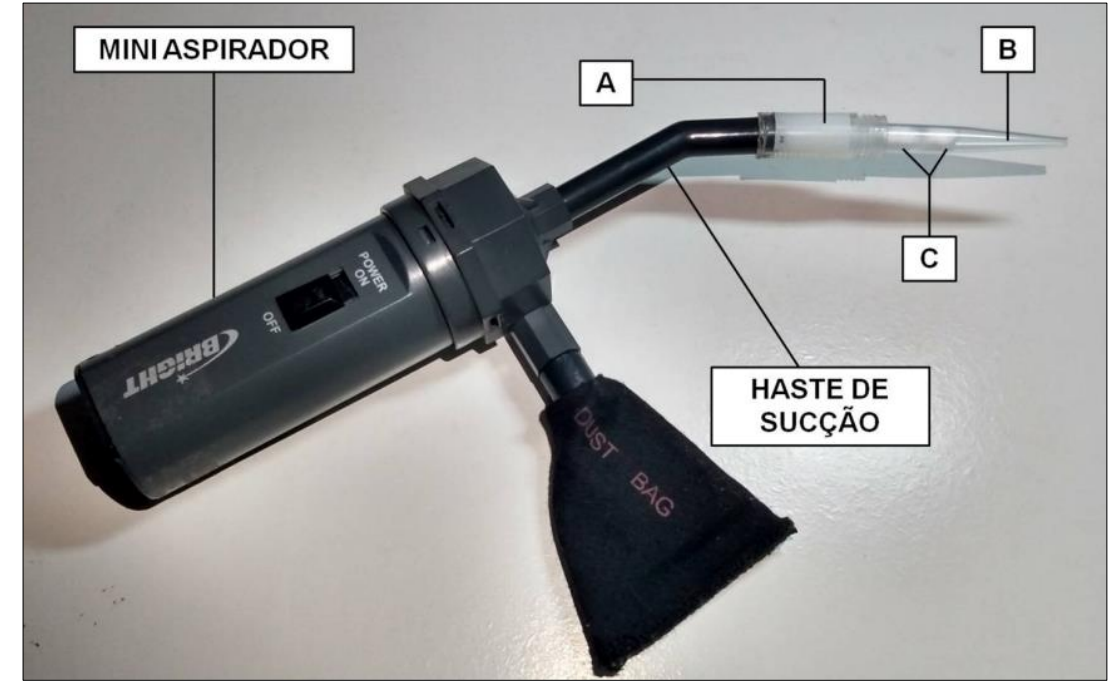


Para garantir a filtragem, dois chumaços de algodão arredondados, de $1,0 \mathrm{~cm}^{3}$, foram inseridos em cada uma, da seguinte forma: o primeiro chumaço era posicionado até a metade da ponteira, sendo mantido a uma distância de aproximadamente $2,5 \mathrm{~cm}$ da abertura anterior e mais estreita, pela qual entra o material aspirado. $\mathrm{O}$ segundo chumaço posicionado a uma distância de $0,3 \mathrm{~cm}$ do primeiro, e de $2,0 \mathrm{~cm}$ da abertura posterior e mais larga (Figura 3), por onde as ponteiras eram encaixadas no tubo criogênico do conjunto funcional do aparelho. Esse desenho mostrou-se eficiente, retendo e isolando nas ponteiras estéreis o material aspirado.

Figura 3 - Esquema do posicionamento dos filtros de algodão dentro das ponteiras. As setas duplas indicam a distância dos chumaços em relação às aberturas da ponteira e entrei si. Setas pretas indicam os nomes das aberturas e dos chumaços. Arte de Ricardo França Alves dos Reis (2020).



Para a coleta em aberturas e orifícios estreitos, ou sob capas e fendas do objeto, foi necessário também acrescentar, alternativamente, na extremidade de aspiração, prolongamentos com dimensão adequada. Dessa forma, sondas uretrais de cerca de 2,5 $\mathrm{mm}$ de espessura, podiam ser removidas de suas embalagens estéreis e conectadas às ponteiras no momento da coleta. Tratando-se de material previamente esterilizado e disponibilizado em sua embalagem original, garantia também a segurança do procedimento. Para facilitar a sucção das amostras, podia ser removido segmento de cerca de $0,5 \mathrm{~cm}$ da parte anterior da sonda, de modo a ampliar a abertura original, evitando-se possível bloqueio da passagem dos aspirados (Figura 4).

Figura 4 - Mini aspirador com a sonda uretral encaixada diretamente na ponteira. Foto de Ricardo França Alves dos Reis (2020).

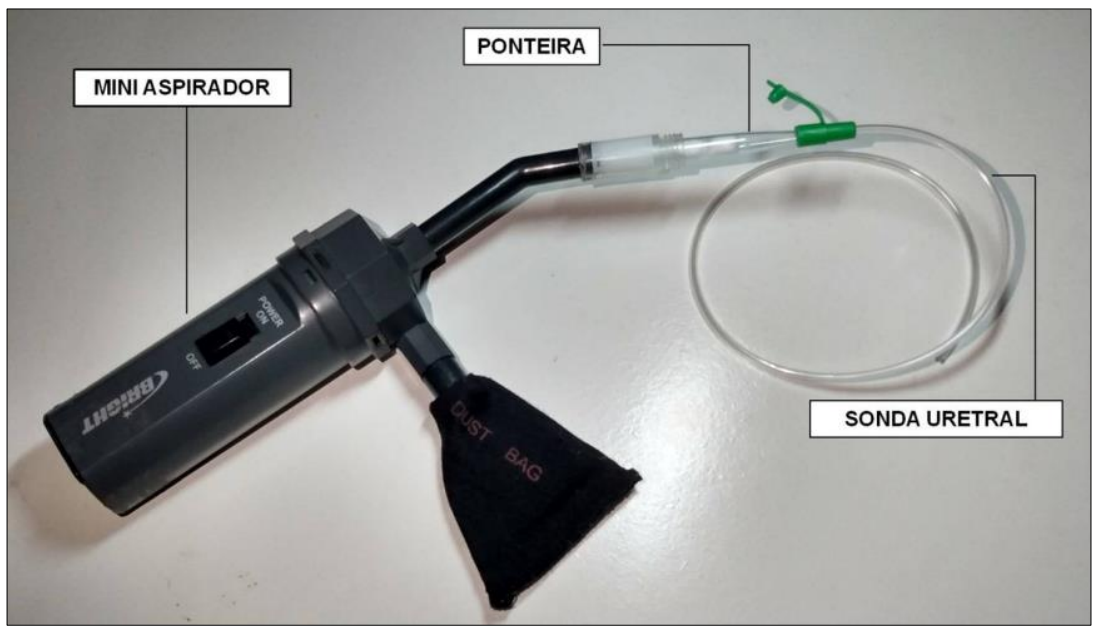


O protótipo do aspirador era passível de ser esterilizado, assim como as respectivas peças descartáveis. $\mathrm{O}$ aparelho provou poder ser higienizado em separado, enquanto as partes pertencentes à extremidade de aspiração, já montadas com filtros de algodão, podiam ser autoclavadas a 120o C. Uma vez usadas para aspiração, as ponteiras contendo amostras, eram levadas ao laboratório de análise e depois descartadas adequadamente. A troca da extremidade de aspiração a cada coleta assegurava maior controle da contaminação biológica cruzada das amostras.

\section{RESULTADOS}

Com esse aspirador adaptado, foram coletadas amostras em dois corpos mumificados da coleção egípcia do Museu Nacional do Rio de Janeiro, onde havia grande preocupação com a proliferação de fungos e seus potenciais riscos aos objetos e à saúde dos que os manipulavam. Foram estudados os corpos mumificados com números de catálogo 170 (corpo de Lactente) e 527 (corpo do sacerdote Hori), vistos aqui na Figura 5 e na Figura 6, respectivamente.

Figura 5 - Múmia de Lactente. Número de catálogo 170. Fonte: Foto de Sheila Maria Ferraz Mendonça de Souza (2013).

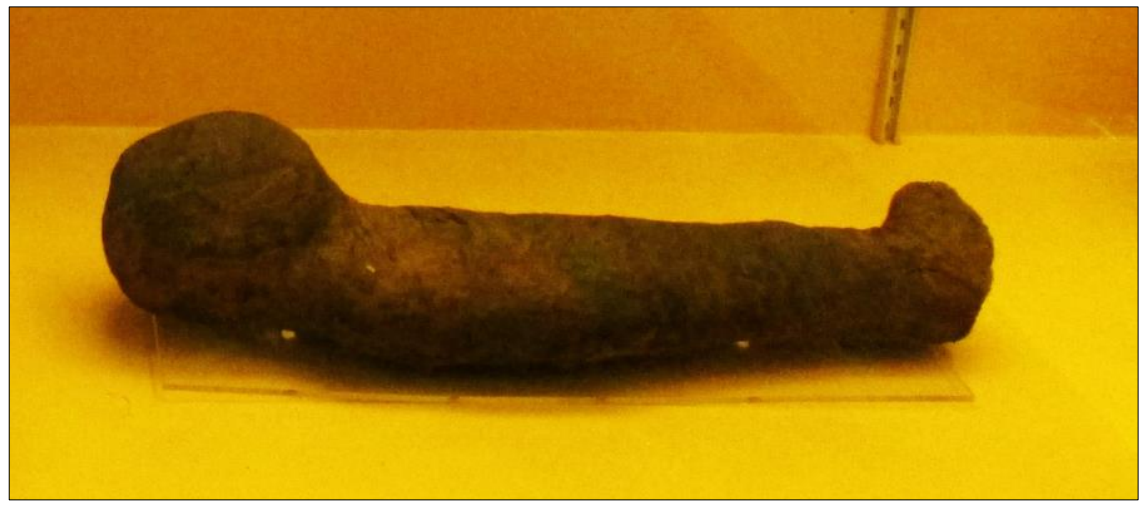

Figura 6 - Múmia do Sacerdote Hori. Número de catálogo 527. Fonte: Foto de Sheila Maria Ferraz Mendonça de Souza (2013).

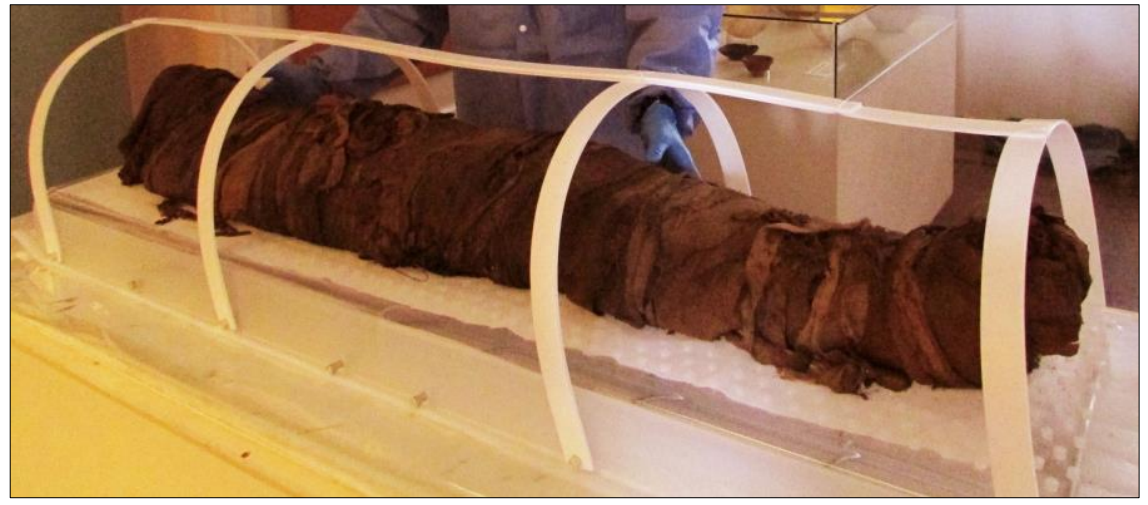

O objetivo da pesquisa para o Mestrado do primeiro autor foi identificar os fungos presentes em amostras superficiais coletadas naquelas múmias, para confirmar ou refutar a hipótese de seu potencial patogênico e risco para a conservação dos exemplares. Tratando-se de acervo mantido por décadas em ambiente de sala de exposição aberta, em vitrines sem isolamento e com histórico de incidentes que causaram intensa proliferação de microrganismos, era necessário fazer coletas adequadas tanto nos corpos quanto no 
ambiente. Para isso, foi proposta metodologia de coleta nas múmias com os melhores cuidados, técnica e equipamento adaptado disponível. Coletas do ar do ambiente da sala de exposição egípcia também foram realizadas, inclusive durante a retirada de amostras naqueles corpos.

Sendo impossível retirar os corpos do Museu, o trabalho prático foi realizado em etapas: 1) preparação de equipamentos e insumos (aspirador higienizado, EPIs esterilizados, instrumental e kits autoclavados); 2) coleta na sala de exposição do Egito, com preparação de espaço adequado, isolamento da área, apoio de equipe Museológica; 3) recolha de amostras aspiradas dos corpos mumificados, recolha de depósitos passivos em placas de Petri, remoção de aspiradores de ar ambiente e transporte do total das amostras coletadas para o Laboratório de Ultraestrutura Celular Hertha Meyer, da Universidade Federal do Rio de Janeiro; 4) semeadura, cultivo e identificação macro e microscópica dos fungos presentes nas amostras.

O mini aspirador foi utilizado com sucesso e permitiu a realização de coletas a seco, na superfície dos corpos, em regiões da cabeça, tórax, perna e pés, sendo as mesmas dirigidas para as áreas escolhidas previamente por apresentarem alterações de cor, depósitos de resíduos, presença de irregularidades e porosidades, além de interstícios da trama do linho que envolvia os corpos, conforme descrito em detalhes na metodologia da dissertação. O procedimento de aspiração permitiu que, atendendo ao solicitado pela curadoria do Museu, fosse feita a remoção de quantidades mínimas dos materiais pulverizados, evitando-se ao máximo a remoção de fragmentos, exceto quando eles apresentavam tamanho de apenas alguns milímetros e já se encontravam desprendidos.

Para fins comparativos, e com o intuito de contribuir para confirmar a funcionalidade do equipamento adaptado, foram utilizados adicionalmente pinças e bisturis para as coletas em áreas onde havia fragmentos desprendidos. Essas coletas foram importantes para proporcionar material comparativo com os resultados obtidos para as amostras coletadas por aspiração. A retirada com pinça e bisturi permitiu também comparar o tempo exigido para ambos os procedimentos.

Para fins de controle, foram obtidas amostras do ar ambiente em diferentes locais da sala egípcia onde foram feitas as coletas, inclusive sobre a mesa de trabalho utilizada. Tal como visto na literatura, a coleta para controle do ambiente deu-se de duas maneiras: de modo passivo (placa de Petri com meio de cultura, aberta) e por aspirador apropriado (modelo AESAP10175, Sampl'air Lite, EUA). Como já mencionado, a aspiração de ar ambiente é muito utilizada para análises sanitárias e de contaminação de recintos para diferentes fins (NITIU et al., 2019). Essas amostras permitiram a comparação entre os microrganismos em suspensão no ar da sala de exposição durante o período da coleta e aqueles identificados nas múmias. Tratando-se de ambiente aberto e exposto à vegetação de grande porte do parque em torno do edifício, a premissa era de grande biodiversidade de propágulos circulando o ar ao qual as peças estavam expostas.

Os resultados obtidos nas diferentes amostras permitiram confirmar que não houve contaminação cruzada entre as coletas feitas com o mini aspirador (REIS, 2014). Não foram observadas diferenças significativas entre as amostras coletadas por aspiração e outros meios. Diferentes tipos de fungos de aspecto filamentoso ou leveduriforme foram isolados, mostrando que o instrumento de coleta não teve influência no resultado dos isolamentos, sendo os gêneros Chaetomium e Cladosporium mais populares, isolados de amostras capturadas tanto com o MAA, quanto com outros instrumentos de coleta (Tabela 1). 
Tabela 1 - Fungos isolados de amostras coletadas das múmias e dos ambientes relacionados a elas, por meio do MAA e demais instrumentos de coleta.

Fonte: Adaptada de Reis (2014, p. 66).

\begin{tabular}{|c|c|c|c|c|}
\hline \multirow{2}{*}{$\frac{\text { Múmia }}{\text { LACTENTE }}$} & \multirow[t]{2}{*}{ Área de coleta } & \multirow[t]{2}{*}{ Instrumento de coleta } & \multicolumn{2}{|c|}{ Aspecto e quantidade de isolados } \\
\hline & & & Leveduriformes & Filamentosos \\
\hline & Cabeça & MAA e sonda & 1 (Cryptococcus) & 0 \\
\hline & Cabeça & MAA & 0 & 0 \\
\hline & Corpo & MAA & 0 & 1 \\
\hline & Pé & MAA & 0 & 1 \\
\hline & Pé & MAA & 0 & 0 \\
\hline & Pé & MAA & 0 & 1 (Chaetomium) \\
\hline & Pé & Pinça & 0 & 1 (Chaetomium) \\
\hline & Cabeça & Pinça, bisturi & 0 & 0 \\
\hline & Corpo & Pinça, bisturi & 0 & 2 \\
\hline & Pé & Pinça, bisturi & 0 & 1 \\
\hline & Vitrine & AAA & 1 & 4 \\
\hline & Próxima da vitrine & AAA & 2 & 4 \\
\hline & $\begin{array}{c}\text { Sobre a maca próxima da } \\
\text { múmia }\end{array}$ & Placa de petri aberta & 2 & 4 \\
\hline \multirow[t]{16}{*}{ HORI } & Bandagem & Alça plástica estéril & 0 & 1 \\
\hline & Bandagem & Tesoura e pinça & 0 & 2 (Cladosporium) \\
\hline & Bandagem & MAA & 0 & 1 (Cladosporium) \\
\hline & Cabeça & MAA & 0 & 0 * \\
\hline & Cabeça & MAA & 0 & $0^{*}$ \\
\hline & Cabeça & MAA & 0 & 0 \\
\hline & Região dos pés & MAA e sonda & 0 & $0 *$ \\
\hline & Região dos pés & MAA & 0 & $0^{*}$ \\
\hline & Superfície do corpo & Pinça & 0 & 0 \\
\hline & Superfície do corpo & Pinça & 0 & $0^{*}$ \\
\hline & Superfície do corpo & Pinça & 0 & $0^{*}$ \\
\hline & Abaixo do corpo & Pinça & 0 & 0 \\
\hline & Sala de exposição & AAA & 0 & 4 \\
\hline & Interior da cápsula & AAA & 0 & 9 \\
\hline & Interior da vitrine & AAA & 0 & 7 \\
\hline & Em cima da cápsula & MAA & 0 & 1 (Paecilomyces) \\
\hline
\end{tabular}

* Crescimento fúngico observado, porém não a partir das amostras coletadas, sendo as colônias consideradas contaminação externa, e portanto descartadas.

MAA: Mini Aspirador Adaptado.

AAA: Amostrador de Ar Automático.

\section{DISCUSSÃO}

O equipamento funcionou tal como nos testes prévios, promovendo coletas satisfatórias realizadas pelos atores, sempre supervisionados pela curadoria do Museu. A cada coleta, as ponteiras e/ou ponteiras com sonda acoplada eram removidas do mini aspirador, e colocadas em bolsa plástica estéril vedada e identificada, para processamento subsequente em câmara de fluxo laminar no laboratório, agilizado o processo de coleta, facilitando o transporte e garantindo a segurança em relação a desperdícios e contaminações acidentais. $O$ processamento das amostras e resultados obtidos no trabalho, disponíveis na dissertação já citada, não serão detalhadas aqui pois constam de artigo em elaboração. O procedimento de aspiração mostrou-se uma boa alternativa ao uso de suabes, embora esses sejam utilizados em pesquisas similares publicadas na literatura (ABDEL-KAREEM, 2010a; CAYCHO et al., 2010). Muito embora não tenha sido propósito da dissertação comparar os resultados de diferentes técnicas de coleta, os resultados obtidos nas culturas de todas as amostras coletadas por aspiração confirmaram a eficácia do protótipo do aparelho. 
Em relação às vantagens do uso do MAA, o tempo despendido para as coletas também foi um diferencial (Gráfico 1). Foram necessários 20 segundos em média para coletar/acondicionar cada amostra e colocar uma nova extremidade de aspiração no aparelho. Sua velocidade de sucção permitiu a captura das amostras quase que instantaneamente, resultando em culturas positivas e suficientes, tornando o processo mais ágil. Já com bisturis e pinças, cada coleta levou cerca de 40 segundos, uma vez que esses instrumentos convencionais precisavam ser submetidos ao aquecimento para esterilização, e subsequente resfriamento, antes de cada uso. $\mathrm{O}$ mini aspirador permitiu coletar o dobro de amostras quando comparado com o bisturi e a pinça, considerado um mesmo espaço de tempo, ou o mesmo número de amostras.

Gráfico 1 - Quantidade de amostras coletadas pelo tempo médio gasto em minutos conforme o instrumento de coleta. Gráfico de Ricardo França Alves dos Reis (2020).

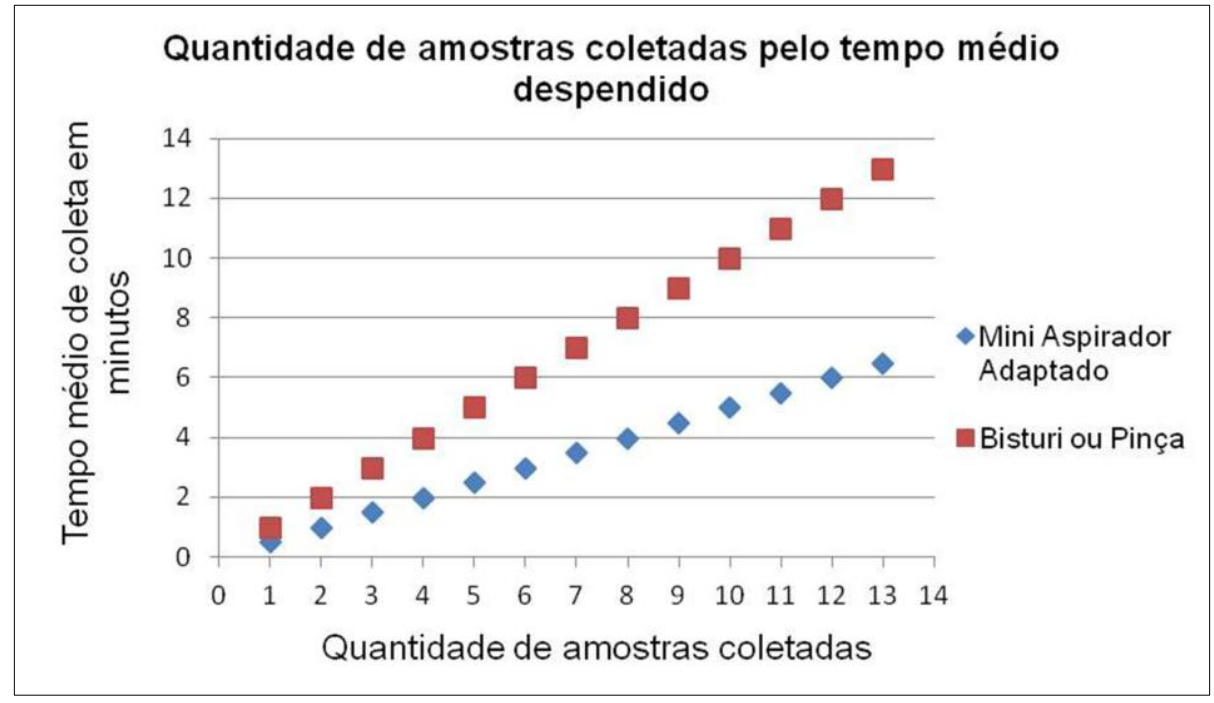

Até onde o estudo foi desenvolvido, e em comparação com outros, as amostras, ainda que de tamanho muito reduzido, forneceram informações importantes e confirmaram a diversidade da microbiota presente no material. Atendendo à principal exigência da curadoria, por um estudo conservador e minimamente invasivo, essa técnica forneceu resultados que responderam à curadoria, quanto aos riscos imediatos no manejo das peças. Foi confirmada a ausência de fungos patogênicos nas superfícies estudadas, tranquilizando a equipe de trabalho na instituição. Também foi confirmada a intensa troca de microbiota com o ambiente externo, de um museu situado em área verde e dotado de ambientes abertos e de ampla circulação de ar externo. Os resultados obtidos, como já dito, foram qualitativos por não terem sido metodologicamente planejados para aspectos quantitativos.

O uso desse tipo de aspirador nos estudos de contaminação biológica de materiais arqueológicos ainda deve ser testado em maior escala, em diferentes materiais e contextos e, claro, em resposta a diferentes perguntas. Será necessário, no futuro, testar aspectos específicos da sua funcionalidade em condições experimentais controladas, para estabelecer os limites de sua aplicação. Certamente, melhorias no protótipo poderão ser propostas, antes da validação da técnica, ainda que não tenham feito parte dos objetivos do projeto no qual o equipamento foi desenvolvido.

Para a finalidade a que se propôs, na pesquisa do primeiro autor, a técnica de coleta mostrou-se eficiente, permitindo que se conhecesse o universo de contaminação superficial nas peças musealizadas onde foi aplicado. Ainda assim, quando comparado a 
outros trabalhos publicados, o uso do MAA parece apresentar vantagens com relação a outras técnicas de coleta, embora possa apresentar resultados semelhantes ao uso de outros métodos (Tabela 2).

Tabela 2 - Aplicabilidade e resultados obtidos com o Mini Aspirador Adaptado comparados àqueles obtidos a partir de outros instrumentos e metodologias de coleta descritos na literatura. Fonte: Ricardo França Alves dos Reis (2020).

\begin{tabular}{|c|c|c|c|}
\hline $\begin{array}{l}\text { Instrumento } \\
\text { ou método de } \\
\text { Coleta }\end{array}$ & Aplicabilidade do Instrumento & $\begin{array}{c}\text { Autores que } \\
\text { utilizaram }\end{array}$ & Resultados \\
\hline $\begin{array}{l}\text { Mini } \\
\text { aspirador } \\
\text { Adaptado - } \\
\text { MAA }\end{array}$ & $\begin{array}{l}\text { Alternativa viável, de baixo custo de } \\
\text { produção e manutenção, fácil } \\
\text { manuseio e com soluções criativas } \\
\text { para imitações apresentadas pela } \\
\text { utilização de instrumentos } \\
\text { convencionais de coleta de amostras; } \\
\text { Aplicável a trabalhos de pesquisa e } \\
\text { conservação de objetos desenvolvidos } \\
\text { em variados ambientes; Passível de } \\
\text { adaptações de acordo com o tipo de } \\
\text { amostra requerida e a superfície onde } \\
\text { ela está localizada; Permite a captura } \\
\text { de material pulverizado impregnado } \\
\text { em tecidos de corpos mumificados e } \\
\text { outros objetos arqueológico; }\end{array}$ & Reis (2014) & $\begin{array}{l}\text { Coleta de amostras em tempo menor } \\
\text { quando comparado ao uso de bisturis, } \\
\text { tesouras e pinças; Manejo das amostras de } \\
\text { forma independente, com transporte } \\
\text { seguro ao laboratório para realização de } \\
\text { análises biológicas; Isolamento de fungos } \\
\text { leveduriformes e filamentos de amostras } \\
\text { da múmia de Lactente, distribuídos entre } \\
\text { os gêneros Cryptococcus, Chaetomium, } \\
\text { Cladophialophora e Curvularia; Isolamento } \\
\text { de fungos do gênero Cladosporium a partir } \\
\text { de uma amostra da múmia Hori, sendo } \\
\text { outras } 5 \text { amostras negativas para fungos. } \\
\text { Isolamento de fungo do gênero } \\
\text { Paecylomices de amostra de poeira } \\
\text { presente sobre a cápsula que protegia essa } \\
\text { múmia. }\end{array}$ \\
\hline \multirow{4}{*}{ Suabes } & \multirow{4}{*}{$\begin{array}{l}\text { Usado para amostragem em materiais } \\
\text { lisos. Consiste no uso de cotonete } \\
\text { estéril que deve ser umedecido em } \\
\text { líquido estéril se a superfície estiver } \\
\text { seca, o que não é necessário quando } \\
\text { molhada. O suabe é aplicado com um } \\
\text { leve movimento para frente e para } \\
\text { trás em várias direções em uma } \\
\text { determinada área (geralmente } 100 \\
\mathrm{~cm}^{2} \text { ) e delimitado por um gabarito. O } \\
\text { suabe é então inserido em um tubo } \\
\text { com um líquido estéril apropriado, } \\
\text { que pode ser o mesmo tipo de líquido } \\
\text { usado para umedecê-lo. A análise é } \\
\text { realizada por cultura semeando o } \\
\text { conteúdo com o suabe, seja } \\
\text { diretamente, seja após diluição. }\end{array}$} & $\begin{array}{l}\text { González } \\
(2015)\end{array}$ & $\begin{array}{l}\text { Instrumentos de coleta descritos e } \\
\text { recomendados pela autora. }\end{array}$ \\
\hline & & $\begin{array}{l}\text { Micheluz et } \\
\text { al. (2016) }\end{array}$ & $\begin{array}{l}\text { Isolamento de diferentes espécies } \\
\text { fúngicas, principalmente dos gêneros } \\
\text { Aspergillus, Penicillium e Cladosporium, das } \\
\text { quais foi feita a análise da produção de } \\
\text { metabólitos secundários; Identificação de } \\
\text { estreita relação entre os metabólitos } \\
\text { detectados das amostras de poeira com } \\
\text { aqueles produzidos pelos fungos isolados. }\end{array}$ \\
\hline & & $\begin{array}{l}\text { Caycho et al. } \\
\text { (2010) }\end{array}$ & $\begin{array}{c}\text { Isolamento de mais de } 100 \text { colônias } \\
\text { fúngicas de } 13 \text { gêneros diferentes, sendo } \\
\text { Cladosporium, Penicillium e Acremonium os } \\
\text { prevalentes. }\end{array}$ \\
\hline & & $\begin{array}{l}\text { Abdel- } \\
\text { Kareem } \\
(2010 a)\end{array}$ & $\begin{array}{c}\text { Isolamento de espécies de fungos dos } \\
\text { gêneros Alternaria, Aspergillus, Chaetomium, } \\
\text { Penicillium e Trichoderma }\end{array}$ \\
\hline \multirow[b]{2}{*}{ Pinças } & \multirow[b]{2}{*}{$\begin{array}{l}\text { Captura de amostras desprendidas ou } \\
\text { cortados com tesoura e/ou bisturi; } \\
\text { Podem ser aplicadas na coleta de } \\
\text { material pulverizado, embora não } \\
\text { sejam indicados devido à } \\
\text { possibilidade de espalhamento e } \\
\text { suspenção do material no ambiente. }\end{array}$} & $\begin{array}{l}\text { Abdel- } \\
\text { Kareem } \\
(2010 a)\end{array}$ & $\begin{array}{c}\text { Isolamento de espécies de fungos dos } \\
\text { gêneros Alternaria, Aspergillus, Chaetomium, } \\
\text { Penicillium e Trichoderma }\end{array}$ \\
\hline & & $\begin{array}{l}\text { Balout e } \\
\text { Roubet } \\
(1986)\end{array}$ & $\begin{array}{l}\text { Isolamento de grande variedade de } \\
\text { espécies de fungos, pertencentes aos } \\
\text { gêneros Aspergillus e Penicillium, variedade } \\
\text { de espécies de fungos hifomicetos como } \\
\text { Alternaria, Paecilomyces, Cladosporium e } \\
\text { Scopulariopsis, entre outros, isolados de } \\
\text { amostras de fragmentos e material } \\
\text { pulverizado, tanto da cavidade abdominal } \\
\text { como das bandagens de linho. }\end{array}$ \\
\hline
\end{tabular}




\begin{tabular}{|c|c|c|c|}
\hline $\begin{array}{l}\text { Instrumento } \\
\text { ou método de } \\
\text { Coleta } \\
\end{array}$ & Aplicabilidade do Instrumento & $\begin{array}{l}\text { Autores que } \\
\text { utilizaram }\end{array}$ & Resultados \\
\hline $\begin{array}{l}\text { Tesouras e/ou } \\
\text { bisturis }\end{array}$ & $\begin{array}{c}\text { Obtenção de partes específicas do } \\
\text { material a ser amostrado, por meio do } \\
\text { corte de amostras de tamanhos pré- } \\
\text { estabelecidos; No caso dos bisturis, } \\
\text { podem ser usados na raspagem de } \\
\text { material agregado, tanto para a } \\
\text { captura de amostras como para } \\
\text { limpeza de uma grande variedade de } \\
\text { objetos. Pouco recomendados para } \\
\text { raspagens em superfícies pouco } \\
\text { rígidas e irregulares, devido ao risco } \\
\text { de cortes desnecessários no material; } \\
\text { Ainda que possam ser empregados na } \\
\text { captura de amostras, poderiam } \\
\text { provocar o espalhamento de resíduos } \\
\text { do corte, e seu formato não seria } \\
\text { adequado para recolha de amostras } \\
\text { particuladas ou pulverizadas } \\
\text { dispersas; Acarreta perdas do } \\
\text { material. }\end{array}$ & Reis (2014) & $\begin{array}{l}\text { Tesouras: isolamento de duas colônias de } \\
\text { fungos filamentosos derivadas de } \\
\text { fragmento de barbante da bandagem da } \\
\text { múmia Hori; Bisturis: isolamento de três } \\
\text { colônias de fungos filamentosos derivadas } \\
\text { de fragmentos do pé e da superfície do } \\
\text { corpo da múmia de Lactente. }\end{array}$ \\
\hline & $\begin{array}{l}\text { Captura de amostras pulverizadas } \\
\text { e/ou poeira depositada sobre } \\
\text { diferentes superfícies; Coleta de }\end{array}$ & $\begin{array}{l}\text { González } \\
(2015)\end{array}$ & $\begin{array}{l}\text { Instrumentos de coleta descritos e } \\
\text { recomendados pela autora. }\end{array}$ \\
\hline $\begin{array}{l}\text { Colher ou } \\
\text { Espátula } \\
\text { Metálica }\end{array}$ & $\begin{array}{c}\text { amostras pulverizadas de } 0,05-0,10 \mathrm{~g} \\
\text { para a determinação de } \\
\text { contaminantes biológicos, como } \\
\text { esporos, fragmentos, alérgenos e } \\
\text { metabólitos de fungos (micotoxinas, } \\
\text { b- } 1,3 \text { glucanos), endotoxinas } \\
\text { bacterianas, ácaros, fragmentos de } \\
\text { insetos. Eliminação de animais. }\end{array}$ & $\begin{array}{l}\text { Balout e } \\
\text { Roubet } \\
(1986)\end{array}$ & $\begin{array}{c}\text { Isolamento de grande variedade de } \\
\text { espécies de fungos, pertencentes aos } \\
\text { gêneros Aspergillus e Penicillium e de } \\
\text { espécies de fungos hifomicetos, como } \\
\text { Alternaria, Paecilomyces, Cladosporium, } \\
\text { Scopulariopsis, entre outros, a partir de } \\
\text { amostras de fragmentos e material } \\
\text { pulverizado da cavidade abdominal e das } \\
\text { bandagens de linho da múmia de Ramsés } \\
\text { II. }\end{array}$ \\
\hline \multirow{3}{*}{$\begin{array}{c}\text { Placa de Petri } \\
\text { exposta ao } \\
\text { ambiente }\end{array}$} & \multirow{3}{*}{$\begin{array}{l}\text { Captação de partículas suspensas no } \\
\text { ar, como propágulos fúngicos e } \\
\text { esporos bacterianos, por meio da } \\
\text { sedimentação espontânea em função } \\
\text { da força da gravidade. Este método } \\
\text { passivo de coleta consiste na } \\
\text { exposição da placa contendo meio de } \\
\text { cultura específico, no ambiente a ser } \\
\text { amostrado, por tempo pré- } \\
\text { estabelecido. }\end{array}$} & Reis (2014) & $\begin{array}{l}\text { Isolamento de fungo leveduriforme da } \\
\text { espécie Cryptococcus laurentii, e quatro } \\
\text { fungos filamentosos dos gêneros Alternara } \\
\text { e Curvularia, com dois exemplares cada, a } \\
\text { partir da exposição da placa ao ambiente } \\
\text { onde se encontrava a múmia de Lactente, } \\
\text { enquanto era realizada a coleta de } \\
\text { amostras da superfície da múmia. }\end{array}$ \\
\hline & & $\begin{array}{c}\text { Rajendran e } \\
\text { Prasad } \\
(2012)\end{array}$ & $\begin{array}{l}\text { Isolamento de fungos e bactérias. Gêneros } \\
\text { e/ou espécies dos organismos isolados } \\
\text { não foram divulgados pelos autores, } \\
\text { sendo informados apenas os } \\
\text { procedimentos de coleta aplicados, assim } \\
\text { como os métodos empregados na } \\
\text { purificação, subcultivo e identificação } \\
\text { microbiológica e bioquímica dos } \\
\text { microrganismos. }\end{array}$ \\
\hline & & $\begin{array}{l}\text { López- } \\
\text { Martínez et } \\
\text { al. (2007) }\end{array}$ & $\begin{array}{l}\text { Isolamento de } 103 \text { colônias fúngicas de } \\
\text { um total de } 706 \text {, coletadas por esse e por } \\
\text { outros métodos, distribuídas entre } 24 \\
\text { gêneros, sendo os mais abundantes } \\
\text { Penicillium, Cladophialophora, Aspergillus, } \\
\text { Rhizopus, Alternaria e Bipolaris. }\end{array}$ \\
\hline
\end{tabular}




\begin{tabular}{|c|c|c|c|}
\hline $\begin{array}{c}\text { Instrumento } \\
\text { ou método de } \\
\text { Coleta } \\
\end{array}$ & Aplicabilidade do Instrumento & $\begin{array}{l}\text { Autores que } \\
\text { utilizaram }\end{array}$ & Resultados \\
\hline & & $\begin{array}{l}\text { Arya et al. } \\
\quad(2001)\end{array}$ & $\begin{array}{l}\text { Isolamento de mais de } 300 \text { colônias } \\
\text { fúngicas de inúmeras espécies } \\
\text { pertencentes aos filos Zygomycota, } \\
\text { Ascomycota e Deuteromycota. }\end{array}$ \\
\hline \multirow[b]{2}{*}{$\begin{array}{l}\text { Placas de Petri } \\
\text { do tipo } \\
\text { RODAC }{ }^{\circledR} \\
\text { (Replicate } \\
\text { Organism } \\
\text { Detection and } \\
\text { Counting) }\end{array}$} & \multirow{2}{*}{$\begin{array}{l}\text { Método utilizado em superfícies lisas } \\
\text { e consiste na aplicação, por meio de } \\
\text { leve pressão, de uma placa de contato, } \\
\text { geralmente uma placa do tipo } \\
\text { RODAC, com um meio de cultura } \\
\text { ligeiramente excedente, } \\
\text { posteriormente incubado para } \\
\text { crescimento, identificação e contagem } \\
\text { das colônias. }\end{array}$} & $\begin{array}{l}\text { González } \\
(2015)\end{array}$ & $\begin{array}{l}\text { Método de coleta descrito e recomendado } \\
\text { pela autora. }\end{array}$ \\
\hline & & $\begin{array}{l}\text { Krake et al. } \\
\quad(1999)\end{array}$ & $\begin{array}{l}\text { Isolamento de grande quantidade de } \\
\text { gêneros fúngicos derivadas de } \\
\text { amostragem em estantes de } \\
\text { armazenamento de manuscritos e salas de } \\
\text { livros raros, além de um } \\
\text { gabinete de metal. Os gêneros prevalentes } \\
\text { foram Penicillium, Basidiomycetes, } \\
\text { Chaetomium, Cladosporium, Aspergillus spp. }\end{array}$ \\
\hline \multirow[b]{2}{*}{$\begin{array}{l}\text { Quadrados de } \\
\text { carpete }\end{array}$} & \multirow{2}{*}{$\begin{array}{l}\text { Método utilizado na microbiologia } \\
\text { clínica para a coleta de amostras em } \\
\text { lesões na pele ou no coro cabeludo, } \\
\text { consistindo na fricção dos quadrados } \\
\text { de carpetes na área a ser amostrada, } \\
\text { com a posterior semeadura em placas } \\
\text { de Petri com meio de cultura } \\
\text { específico; Pode ser aplicado como } \\
\text { forma alternativa para a captura de } \\
\text { amostras em corpos mumificados e } \\
\text { em superfícies de paredes internas e } \\
\text { externas de museus e outros } \\
\text { ambientes. }\end{array}$} & $\begin{array}{l}\text { Caycho et al. } \\
\quad(2010)\end{array}$ & $\begin{array}{c}\text { Isolamento de mais de } 100 \text { colônias de } \\
\text { fungos, de } 13 \text { gêneros diferentes, sendo } \\
\text { Cladosporium, Penicillium e Acremonium os } \\
\text { prevalentes. }\end{array}$ \\
\hline & & $\begin{array}{l}\text { López- } \\
\text { Martínez et } \\
\text { al. }(2007)\end{array}$ & $\begin{array}{l}\text { Isolamento de } 603 \text { colônias fúngicas, } \\
\text { derivadas de múmias e muros do museu. } \\
\text { No total, foram } 706 \text { colônias coletadas } \\
\text { por meio deste e por outros métodos de } \\
\text { coleta, distribuídas em } 24 \text { gêneros, sendo } \\
\text { os mais abundantes Penicillium, } \\
\text { Cladophialophora, Aspergillus, } \\
\text { Rhizopus, Alternaria e Bipolaris. }\end{array}$ \\
\hline $\begin{array}{l}\text { Fita Adesiva } \\
\text { de Celofane }\end{array}$ & $\begin{array}{l}\text { Captura de amostras em superfícies } \\
\text { lisas, por meio do pressionamento } \\
\text { leve de fita impregnada com } \\
\text { substância adesiva na superfície a ser } \\
\text { amostrada e posterior identificação } \\
\text { das partículas aprisionadas através de } \\
\text { um microscópio; Não pode ser usado } \\
\text { para determinar concentrações de } \\
\text { microrganismos e geralmente não } \\
\text { permite a caracterização deles em } \\
\text { nível de espécie. }\end{array}$ & $\begin{array}{l}\text { González } \\
\text { (2015) }\end{array}$ & $\begin{array}{c}\text { Método de coleta descrito e recomendado } \\
\text { pela autora. }\end{array}$ \\
\hline $\begin{array}{l}\text { Aspirador } \\
\text { Semi } \\
\text { Industrial } \\
\text { adaptado com } \\
\text { filtro de pano }\end{array}$ & $\begin{array}{l}\text { Técnica de higienização; Remoção de } \\
\text { poeira e outras partículas presentes } \\
\text { em livros e documentos. }\end{array}$ & $\begin{array}{l}\text { Spinelli } \\
(2010)\end{array}$ & $\begin{array}{c}\text { Limpeza de livros e documentos com } \\
\text { remoção e retenção de poeira e partículas } \\
\text { de papel }\end{array}$ \\
\hline $\begin{array}{l}\text { Aspirador } \\
\text { Doméstico } \\
\text { adaptado com } \\
\text { novos sacos de } \\
\text { coleta }\end{array}$ & $\begin{array}{l}\text { Captura de poeira depositada em } \\
\text { pisos para posterior investigação } \\
\text { microbiológica da presença de fungos } \\
\text { e de metabólitos secundários } \\
\text { produzidos por eles. }\end{array}$ & $\begin{array}{l}\text { Micheluz et } \\
\text { al. (2016) }\end{array}$ & $\begin{array}{l}\text { Isolamento de diferentes espécies } \\
\text { fúngicas, principalmente dos gêneros } \\
\text { Aspergillus, Penicillium e Cladosporium, das } \\
\text { quais foi feita a análise da produção de } \\
\text { metabólitos secundários; Identificação de } \\
\text { estreita relação entre os metabólitos } \\
\text { detectados das amostras de poeira com } \\
\text { aqueles produzidos pelos fungos isolados. }\end{array}$ \\
\hline
\end{tabular}




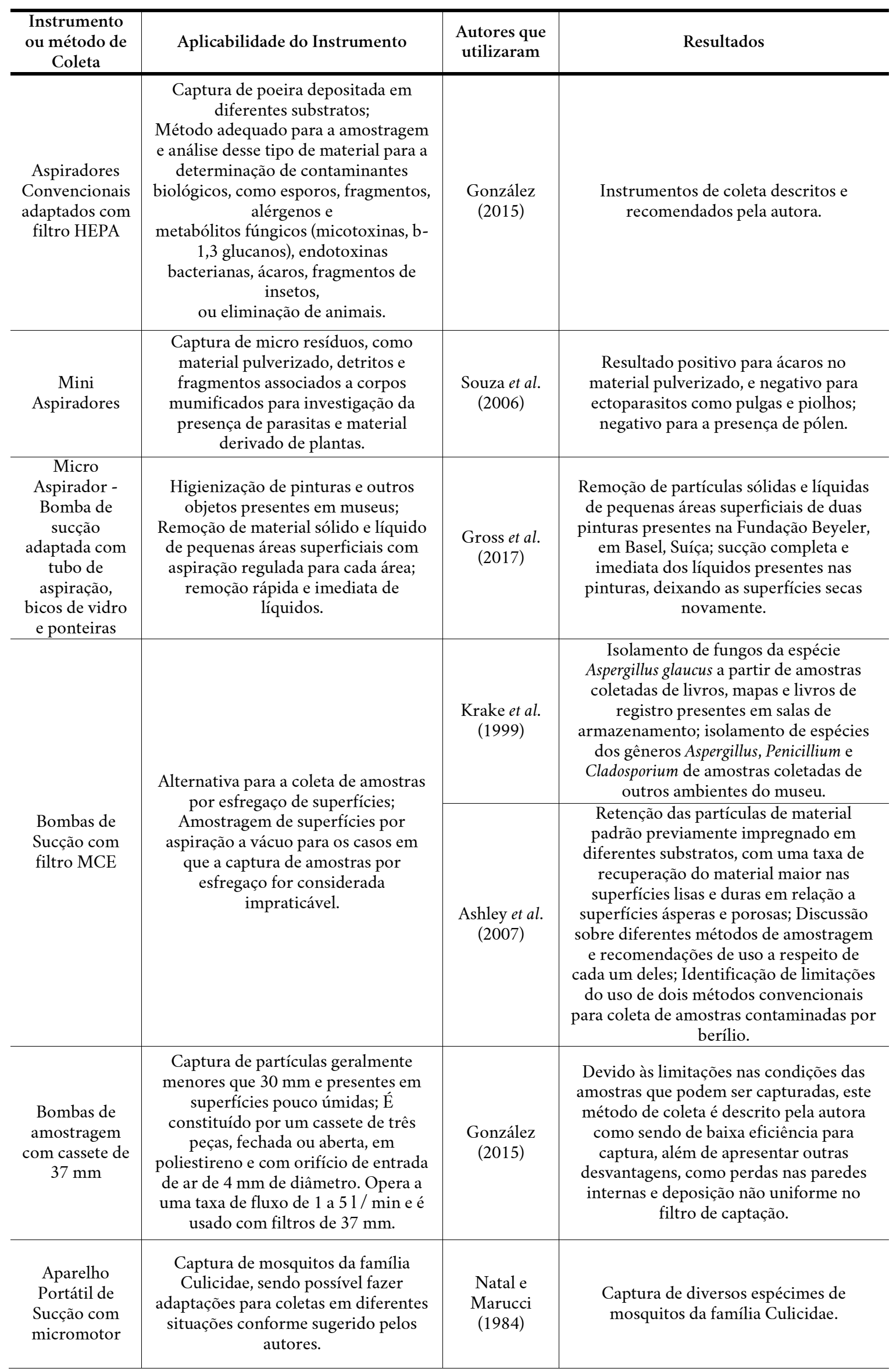




\begin{tabular}{c|c|c|c}
\hline $\begin{array}{c}\text { Instrumento } \\
\text { ou método de } \\
\text { Coleta }\end{array}$ & Aplicabilidade do Instrumento & $\begin{array}{c}\text { Autores que } \\
\text { utilizaram }\end{array}$ & Resultados \\
\hline Coletor de & $\begin{array}{c}\text { Coleta de ácaros que habitam plantas, } \\
\text { com retenção dos indivíduos em } \\
\text { frascos; Alternativa para a coleta feita } \\
\text { com pincéis umedecidos, conforme } \\
\text { preconizado para a captura desses } \\
\text { organismos. }\end{array}$ & $\begin{array}{c}\text { Zacarias e } \\
\text { Anibal } \\
(2000)\end{array}$ & $\begin{array}{c}\text { Coleta de espécimes de diferentes espécies } \\
\text { de ácaros que habitam plantas. }\end{array}$ \\
\hline
\end{tabular}

Cabe lembrar que esse aparelho, sendo movido a pilhas convencionais, e com tempo de autonomia de funcionamento de cerca de 2 horas, mostrou-se ferramenta prática, de baixo custo e de fácil manejo. A redução no tempo de manipulação, ou exposição do objeto, e simplificação do material necessário ao trabalho de coletas, inclusive eliminando a necessidade de esterilização dos instrumentos a cada coleta, além de reduzir o tempo de trabalho, sugere um potencial uso também para coletas de campo.

Ideias inovadoras em relação a equipamentos de aspiração ou sucção de pequeno porte têm sido observadas ao longo dos anos. Contudo, nenhuma que tenha sido recentemente desenvolvida, além de não ter sido verificada nenhuma inovação voltada para coleta e análise de fungos em material arqueológico. Outros usos de técnicas de aspiração, tal como indicado no início deste artigo, têm sido desenvolvidos na área da saúde e dos estudos biomédicos, como os dois exemplos que se seguem. Natal e Marucci (1984) que desenvolveram um aparelho portátil de sucção que funcionava com um micromotor de uso geral de $6.000 \mathrm{rpm}$, para captura de mosquitos da família Culicidae. Zacarias e Anibal (2000), que desenvolveram um coletor de ácaros por sucção, equipamento simples e eficaz para coletar ácaros que habitam plantas, onde os indivíduos capturados ficam retidos em frascos. Esse tipo de coletor, um tubo flexível com recipiente adaptado, não utilizava sucção mecânica, sendo feita pela boca do indivíduo que coletava, e substituiu a coleta feita com pincéis umedecidos, preconizada anteriormente.

Um exemplo de uso de aspiração para coleta de material micro particulado, que não foi citado na época do Mestrado, foi proposto por Ashley et al. (2007). Buscando avaliar o potencial de exposição humana às substâncias tóxicas presentes em poeira superficial, os autores testaram métodos padronizados para a coleta de amostras de poeira e realizaram sua posterior análise. A coleta por aspiração a vácuo foi proposta como alternativa à coleta de esfregaço de superfícies, quando essa fosse impraticável. Seguindo um padrão para coleta por micro amostragem da Sociedade Americana de Testes e Materiais (ASTM Standard D7144, 2005), os autores utilizaram uma bomba de amostragem pessoal (AirCheck 2000 Modelo 210-2002), acoplada por meio de tubo flexível a um filtro em MCE (Membrana de Ester Celulose Mista).

Ao realizarem a análise de alguns métodos padronizados e não padronizados para coletas de poeira por aspiração a vácuo, os autores identificaram vantagens e desvantagens entre eles que envolviam o custo e a manutenção dos instrumentos utilizados, as condições de isolamento das amostras, os riscos para o operador dos aparelhos, a quantidade de amostras obtidas, as limitações de coleta conforme o substrato, além da facilidade de manuseio do equipamento. Dois modelos-padrão de aspiradores foram testados para avaliar o potencial para a captura de amostra contaminada por berílio, um metal tóxico cuja inalação pode acarretar riscos à saúde. Contudo, ambos os aspiradores apresentaram limitações, que fizeram os autores sugerir a criação de um novo modelo ou adaptações em modelos já existentes, considerando as seguintes características:

(a) devem ser fáceis de usar; (b) eles devem ser de baixo custo; (c) devem eliminar a contaminação cruzada; (d) seu uso não deve causar poeira assentada que pode ser 
transportada no ar; (e) as amostras devem ser fáceis de transportar; e (f) a preparação e análise da amostra subsequente deve ser direta e descomplicada (ASHLEY et al., 2007).

O estudo de Ashley et al. (2007) poderá ajudar a desenhar um experimento para a validação do mini aspirador apresentado no presente artigo. E vale destacar que os autores consideraram na sua avaliação as mesmas características que valorizamos no nosso protótipo, a saber: facilidade de uso, custo, segurança, controle de contaminação e portabilidade. Nesse sentido, o mini aspirador adaptado atendeu à maioria delas.

Alguns outros estudos ainda poderiam ser citados, comparando técnicas de coleta. Krake et al. (1999) sobre sintomas respiratórios e a contaminação microbiológica em escritórios e um museu localizados em um edifício antigo, utilizaram diferentes métodos para a coleta de amostras superficiais e do ar: o pressionamento por meio de fita de celofane ou de placas de Petri do tipo RODAC ${ }^{\circledR}$ (Replicate Organism Detection and Counting) preenchidas com Ágar de Extrato de Malte (MEA) contra superfícies, e a aspiração com bomba de ar a vácuo e filtros MCE do ar do ambiente. Micheluz et al. (2016), tentaram detectar a presença de metabólitos secundários de fungos em uma biblioteca universitária em Veneza, Itália, coletando amostras de fungos em livros, no ar ambiente e na poeira depositada no piso, usando diferentes técnicas desde suabes até a aspiração e a deposição passiva em Placas de Petri.

Esses estudos, assim como os demais sumarizados na Tabela 2, deixam claro que é fundamental haver um instrumento voltado para cada tipo de amostra, como no caso da poeira do ambiente, dada as suas características físico-químicas e os locais/substratos de coleta, além, é claro, das perguntas que motivam cada coleta, de tal forma que garanta a captura segurada das amostras, permitindo sua análise posteriormente.

O protótipo desenvolvido para coleta de amostras pulverizadas aqui apresentado, tal como outros desenvolvidos para atender a diferentes campos da pesquisa, apresentou bom resultado em seu uso experimental na dissertação do autor, potencial reconhecido pelos pares (REIS; SOUZA, 2016; REIS, 2017), ineditismo confirmado pelo setor de patentes da Fiocruz e, em que pese a necessidade de testagem em maior escala, poderá futuramente atender a outras demandas práticas no campo da conservação dos acervos arqueológicos e de outros materiais. Outras adaptações poderão ser incorporadas ao equipamento, como por exemplo, tubo flexível com um cassete de filtro que permitiria a coleta de amostras úmidas. As necessidades de campo e laboratório, no caso do uso em arqueologia, trarão certamente novas demandas e ideias.

Finalmente, cabe ressaltar que o equipamento adaptado, tendo um custo baixo, tanto para sua aquisição e adaptação, quanto para sua manutenção, pode ser uma solução adequada a nossa realidade institucional. A adaptação utiliza peças de fácil obtenção, como as ponteiras e outros tubos e sondas disponíveis em laboratórios convencionais da área biomédica e no comércio. Sua adaptação, ainda que artesanal, pode ser feita com segurança. Seu pequeno tamanho, e reduzido conjunto de acessórios para as coletas, permite a montagem de kits leves e de tamanho compatível com as necessidades da maior parte das equipes de arqueologia, mesmo para trabalho em campo.

\section{CONCLUSÃO}

O protótipo do mini aspirador adaptado mostrou-se um equipamento eficiente, seguro, e confiável, além de econômico e prático para coletar amostras de microrresíduos, assegurando proteção contra contaminações cruzadas e coletas sucessivas para fins microbiológicos. A solução de ponteiras/extremidades descartáveis, além de assegurar manejo independente das amostras, oferece adicionalmente proteção 
ao seu transporte ao laboratório em segurança, mantendo-as íntegras para realização de análises biológicas.

Pelas vantagens apresentadas, desempenho e resultados satisfatórios quanto à coleta de fungos, o mini aspirador se apresenta como uma alternativa viável, de baixo custo, fácil manuseio e uma solução criativa para problemas enfrentados na coleta de amostras em trabalhos de pesquisa e de conservação em Museus.

Futuros testes em escala adequada e outras aplicações deverão somar dados a proposta desse produto, reconfirmar as vantagens e segurança deste inovador modelo adaptado de utilidade e trazer contribuições para o melhoramento desta técnica de coleta de amostras a seco.

\section{AGRADECIMENTOS}

À Comissão de Propriedade Intelectual da Fundação Oswaldo Cruz, por avaliar e confirmar o ineditismo da adaptação e o seu potencial de aplicação para diferentes tipos de análises em diferentes áreas do conhecimento.

Ao Museu Nacional e sua equipe técnica, pela oportunidade e suporte concedidos para o desenvolvimento do trabalho com as múmias da coleção egípcia.

À Escola Nacional de Saúde Pública Sergio Arouca - ENSP/Fiocruz, pelo apoio e incentivo ao desenvolvimento e aprimoramento das pesquisas com o mini aspirador.

À Dra Juliana Furniel Dutra Santiago, pelo suporte no trabalho realizado com o mini aspirador e pela orientação ao primeiro autor no decorrer da dissertação.

Ao Laboratório de Ultraestrutura Celular Hertha Meyer, IBCCF, UFRJ, pela disponibilidade do espaço e infraestrutura para o processamento das amostras coletadas e isolamento fúngico.

À professora Maria Camila Patiño Ramirez, da Universidade Militar Nueva Granada, Bogotá, Colômbia, pela tradução do resumo para o idioma espanhol. 


\section{REFERÊNCIAS BIBLIOGRÁFICAS}

ABDEL-KAREEM, Omar. Fungal deterioration of historical textiles and approaches for their technical paper control in Egypt. e-Preservation Science. 7, p. 40-47, 2010a. Disponível em: http://www.morana-rtd.com/e-preservationscience/2010/Abdel-Kareem-15-01-2010.pdf.

Acesso em: 4 nov. 2020.

ARYA, Arun; SHAH, Abdul R.; SADASIVAN, Satish. Indoor aeromycoflora of Baroda museum and deterioration of Egyptian mummy. Current Science, 81(7), p. 793-799, 2001. Disponível em: https://www.researchgate.net/publication/242090475. Acesso em: 4. Nov. 2020.

ASHLEY, Kevin; APPLEGATE Gregory T.; WISE Tamara J.; FERNBACK Joseph E.; GOLDCAMP Michael J. Evaluation of a Standardized Micro-Vacuum Sampling Method for Collection of Surface Dust. Journal of Occupational and Environmental Hygiene, 4:3, p. 215-223, 2007. doi: 10.1080/15459620601177461. Disponível em: https://www.tandfonline.com/doi/full/10.1080/15459620601177461? needAccess=true.

Acesso em: 1 nov. 2020.

BALOUT, Lionel ; ROUBET, Colette. Échantillons prélevés sur et sous Ramsés II. In: La momie de Ramsés II: Contribution Scientifique à l'Égyptologie. 1976-1977. Paris, Édition Recherche sur lês Civilizations/ Muséum National d'Histoire Naturelle/ Musée de l'Homme, 1985. p. 60-63. ISBN: 2865381335.

CAYCHO, Katherine L. S.; PARIAN, Raquel M. S.; HUAMANTUPA, Carmen A. V. Micoflora en muros, tejidos y momias del Museo Regional Adolfo Bermúdez Jenkins de Ica. Universidad Nacional San Luis Gonzaga de Ica/ Facultad de Ciencias/ Escuela Academico Profesional de Biología, 2010. Disponível em: https://pt.scribd.com/document/61237920/Micoflora-enMuseo-100. Acesso em: 4 nov. 2020.

GONZÁLEZ, María de L.A.O.C. Calidad del aire interior. Contaminantes biológicos (II). Tipos de muestreo. Instituto Nacional de Seguridad Higiene em el Trabajo (INSHT). Notas Técnicas de Prevención. n. 1065, p. 1-6, 2015. Disponível em: https://saludlaboralydiscapacidad.org/wpcontent/uploads/2019/04/NTP-1065-Calidad-del-aire-interior-Contaminantesbiol\%C3\%B3gicos-2-Tipos-de-muestreo.pdf. Acesso em: 5 nov. 2020.

GRANATO, Marcus. Conservação e restauração de Instrumentos científicos históricos. In: GRANATO, M.; SANTOS, Claudia P.; ROCHA, Claudia R. A. Conservação de Acervos. Museu de Astronomia e Ciências Afins. MAST Colloquia. Rio de Janeiro: MAST, v. 9, p 121-144, 2007. Disponível em: http://site.mast.br/hotsite_mast_colloquia/pdf/mast_colloquia_9.pdf. Acesso em: 2 nov. 2020.

GROSS, Markus; SCHERRER, Nadim; STECKLING, Friederike; ZUMBÜHL, Stefan. Studio Tip: Future Prospects of Conservation Treatments with a Micro-Aspirator Tool. AIC Paintings Specialty Group Postprints, 30, p. 115-119, 2017. doi: 10.24451/arbor.8083. Disponível em: https://arbor.bfh.ch/8083. Acesso em: 14 dez. 2020.

KOLLER, M. Surface cleaning and conservation. Conservation, v. 15, n. 3. 2000. Disponível em: https://www.getty.edu/conservation/publications_resources/newsletters/153/feature.html. Acesso em: 6 nov. 2020.

KRAKE, Ann M.; WORTHINGTON, Karen A.; WALLINGFORD, Kenneth M.; MARTINEZ, Kenneth F. Evaluation of Microbiological Contamination in a Museum. Applied Occupational and Environmental Hygiene, 14: 8, p. 499-509, 1999. doi: 10.1080/104732299302468. Disponível em: https://www.tandfonline.com/doi/abs/10.1080/104732299302468. Acesso em: 3 dez. 2020.

LIMA e SILVA, Francelina H. A. Segurança e saúde do profissional em conservação. In: GRANATO, M; SANTOS, C. P.; ROCHA, C.R.A. Conservação de Acervos. Museu de Astronomia e Ciências Afins. MAST Colloquia. Rio de Janeiro: MAST, v. 9, p. 165-174, 2007. Disponível em: http://site.mast.br/hotsite_mast_colloquia/pdf/mast_colloquia_9.pdf. Acesso em: 2 nov. 2020. 
LÓPEZ-MARTÍNEZ, Rubén; HERNÁNDEZ-HERNÁNDEZ, Francisca; MILLÁN-CHIU, Blanca E.; MANZANO-GAYOSSO, Patricia; MÉNDEZ-TOVAR, Luis J. Effectiveness of imazalil to control the effect of fungal deterioration on mummies at the Mexico City Museum 'El Carmen (article in Spanish). Revista Iberoamericana de Micología, 24 (4), p. 283-288, 2007. doi: 10.1016/S1130-1406(07)70057-8. Disponível em: http://www.reviberoammicol.com/200724/283288.pdf. Acesso em: 4 nov. 2020.

MARIAT, François; C. ADÁN-CAMPOS. La technique du carré de tapis, méthode simple de prélèvement dans les mycoses superficielles. Ann. Institut Pasteur. 113, p. 666-668, 1967. Disponível em: https://gallica.bnf.fr/ark:/12148/bpt6k6436869m/f214.item. Acesso em: 15 jan. 2021.

MICHELUZ, Anna; SULYOK, Michael; MANENTE, Sabrina; KRSKA, Rudolf; VARESE, Giovanna C.; RAVAGNAN, Giampietro. Fungal secondary metabolite analysis applied to Cultural Heritage: the case of a contaminated library in Venice. World Mycotoxin Journal, 9 (3): p. 397-407, 2016. doi: 10.3920/WMJ2015.1958. Disponível em: https://www.wageningenacademic.com/doi/10.3920/WMJ2015.1958. Acesso em: $3 \mathrm{dez}$. 2020.

NATAL, Délsio; MARUCCI, Daniel. Aparelho de sucção tipo aspirador para captura de mosquitos. Rev. Saúde Pública, São Paulo, v. 18, n. 5, p. 418-420, 1984. doi: 10.1590/S003489101984000500013. Disponível em: https://www.scielo.br/scielo.php? script=sci_arttext\&pid=S0034-89101984000500013\&lng=pt\&tlng=pt. Acesso em: 13 nov. 2020.

NITIU, Daniela S.; MALLO, Andrea C.; ELÍADES, Lorena A.; SANTA CRUZ, Mauro G.; SAPARRAT, Mario C. Fungal Monitoring In An Exhibition Room With Egyptian Mummies In The Museum Of Natural Sciences Of La Plata, Argentina. International Journal of Conservation Science. v. 10, n. 2, p. 291-306, 2019. Disponível em: http://ijcs.ro/public/IJCS-1926_Nitiu.pdf. Acesso em: 18 jun. 2020.

ODDY, A. Does Reversibility Exits in Conservation? British Museum Occasional Paper, London, n. 135, 1999. p. 1- 5. In: GRANATO M.; SANTOS, Claudia P.; ROCHA, Claudia, R. A.. Conservação de Acervos. Museu de Astronomia e Ciências Afins. MAST Colloquia. Rio de Janeiro: MAST, 2007. p. 127. Disponível em: http://site.mast.br/hotsite_mast_colloquia/pdf/ mast_colloquia_9.pdf. Acesso em: 2 nov. 2020.

RAJENDRAN, Ramasamy; PRASAD, Nisy A. Study on the indoor and outdoor microflora associated with the biodeterioration of mural paintings at Sekharaipuram Vishnu temple, Adakkaputhur, Palakkad, Kerala, India. International Journal of Environmental Sciences and Research, 1 (4), p. 104-108, 2012. Disponível em: https://shodhganga.inflibnet.ac.in/ bitstream/10603/43421/17/17_publication.pdf. Acesso em: 4 nov. 2020.

REIS, Ricardo F. A. Isolamento e identificação de fungos em amostras retiradas de múmias egípcias da coleção do Museu Nacional do Rio de Janeiro. Dissertação de Mestrado em Saúde Pública. Rio de Janeiro. Escola Nacional de Saúde Pública Sergio Arouca, Fundação Oswaldo Cruz, 2014. 109pp. Disponível em: https://www.arca.fiocruz.br/handle/icict/20500. Acesso em: 2 nov. 2020.

REIS, Ricardo F. A; SOUZA, Sheila M. de. Sampling of Microorganisms from Egyptian Mummies at the National Museum of Rio de Janeiro, Brazil: A successful adaptation of a vacuum cleaner model. In: 9th World Congress on Mummy Studies by mummy, Lima, Peru, 2016. p. 177. Disponível em: https://issuu.com/mummy.congressperu/docs/libro_de_resumenes Acesso em: 15 jan. 2021.

REIS, Ricardo F. A. Sampling of Microorganisms from Egyptian Mummies at the National Museum of Rio de Janeiro, Brazil: A successful adaptation of a vacuum cleaner model. In: American Institute for Conservation 45th Annual Meeting, Chicago, Illinois, May 26-June 2, 2017. p. 115. Disponível em: https://www.culturalheritage.org/docs/default- 
source/publications/periodicals/annual-meeting/am2017-abstractbook.pdf?sfvrsn= f112464e_14. Acesso em: 15 jan. 2021.

SOCIEDADE BRASILEIRA DE PATOLOGIA CLÍNICA/MEDICINA LABORATORIAL (SBPC/ML): Boas Práticas em Microbiologia Clínica. São Paulo, 2014. Disponível em: http://www.sbpc.org.br/upload/conteudo/Microbiologia.pdf Acesso em: 14 nov. 2020.

SOUZA, Sheila M. de. Múmias egípcias milenares - viagens não-invasivas. In. Heron Werner; Jorge Lopes (Eds.) Paleontologia, arqueologia, fetologia. Tecnologias 3D. Rio de Janeiro: Verinter. 1, 2009. p. 77-104. ISBN: 9788537202319.

SOUZA, Sheila M. de; REINHARD, Karl J; LESSA, Andrea. Cranial deformation as the cause of death for a child from the Chillon River Valley, Peru. CHUNGARA. Revista de Antropologia Chilena: 40(1), p. 41-53, 2008. doi: 10.4067/S0717-73562008000100005. Disponível em: https://scielo.conicyt.cl/pdf/chungara/v40n1/art05.pdf. Acesso em: 13 dez. 2020.

SOUZA, Daniela L. de; GUERRA, Rita de M.S.N de C.; SOUZA, Sheila M. de; FERREIRA, Luiz Fernando; ARAUJO, Adauto. Acari found in a mummy bundle from the Chillon River Valley, Peru. Paleopathology Newsletter 136, p. 11-16, 2006. .Disponível em: http://cpfera.fiocruz.br/docs/pubs/Article152.pdf. Acesso em: 15 jan. 2021.

SPINELLI, Jayme. Recomendações para a higienização de acervos bibliográficos \& documentais. Biblioteca Nacional, 2010. Disponível em: http://www.bn.br/portal/arquivos/pdf/higienizacao_Jaime.pdf. Acesso em: 17 nov. 2020.

TOCCHETTO, Fernanda B.; SALLÉS, Jaime M.; ALVES, Clarice da S.; DODE, Susana dos S.; SOUZA, Taciane S.; SILVA, Fabio B. da; DUTRA, Márcia R. R.; MEDEIROS, Eneri J. B.; DOMINGUES, Bibiana S. Protocolo de ingresso de acervos arqueológicos em instituições de guarda e pesquisa: uma proposta do LÂMINA/UFPel e do Museu de Porto Alegre Joaquim Felizardo, RS. Revista Arqueologia Pública, Campinas, SP, v. 11, n. 2[19], p. 6-24, 2017. doi: 10.20396/rap.v11i2.8649829. Disponível em: https://periodicos.sbu.unicamp.br /ojs/index.php/rap/article/view/8649829. Acesso em: 14 dez. 2020.

VALENTÍN, Nieves. Microbial contamination in archives and museums: Health hazard and preventive strategies using air ventilation systems. The Getty Conservation Institute, p. 1-26, 2007. Disponível em: http://www.getty.edu/conservation/our_projects/science/climate/ paper_valentin.pdf. Acesso em: 2 nov. 2020.

VALENTÍN, Nieves. Análisis y control del biodeterioro. A las plagas les gustan las momias. In: Momias. Manual de buenas prácticas para su preservación. IPCE. Ministerio de Educación, Cultura y Deporte, p. 99-131, 2012. ISBN: 978-84-8181-524-5.

ZACARIAS, Mauricio S; OLIVEIRA, Anibal R. Coletor de ácaros por sucção. An. Soc. Entomol. Bras., Londrina, v. 29, n. 4, p. 827-830, 2000. doi: 10.1590/S0301-80592000000400025. Disponível em: https://www.scielo.br/pdf/aseb/v29n4/v29n4a25.pdf. Acesso em: 13 nov. 2020. 